\title{
Ocean temperature and salinity components of the Madden-Julian oscillation observed by Argo floats
}

\author{
Adrian J. Matthews - Patama Singhruck - Karen J. Heywood
}

Received: date / Accepted: date

\begin{abstract}
New diagnostics of the Madden-Julian oscillation (MJO) cycle in ocean temperature and, for the first time, salinity are presented. The MJO composites are based on 4 years of gridded Argo float data from 2003-2006, and extend from the surface to $1400 \mathrm{~m}$ depth in the tropical Indian and Pacific Oceans. The MJO surface salinity anomalies are consistent with precipitation minus evaporation fluxes in the Indian Ocean, and with anomalous zonal advection in the Pacific. The Argo sea surface temperature and thermocline depth anomalies are consistent with previous studies using other data sets. The near-surface density changes due to salinity are comparable to, and partially offset, those due to temperature, emphasising the importance of including salinity as well as temperature changes in mixedlayer modelling of tropical intraseasonal processes. The MJO-forced equatorial Kelvin wave that propagates along the thermocline in the Pacific extends down into the deep ocean, to at least $1400 \mathrm{~m}$. Coherent, statistically significant, MJO temperature and salinity anomalies are also present in the deep Indian Ocean.
\end{abstract}

Adrian Matthews

School of Environmental Sciences and School of Mathematics

University of East Anglia, UK

E-mail: a.j.matthews@uea.ac.uk

Patama Singhruck

School of Environmental Sciences

University of East Anglia, UK

Present address: Department of Marine Science

Chulalongkorn University, Bangkok, Thailand

E-mail: patama.s@chula.ac.th

Karen Heywood

School of Environmental Sciences

University of East Anglia, UK

E-mail: k.heywood@uea.ac.uk
Keywords intraseasonal oscillation · MJO - equatorial Kelvin wave $\cdot$ Argo $\cdot$ salinity

\section{Introduction}

The MJO (Madden and Julian, 1971) is the dominant mode of intraseasonal variability in the tropical atmosphere. It consists of large $(10,000 \mathrm{~km}$ across $)$ positive and negative convective cloud anomalies that propagate eastward across the warm pool region, from the Indian Ocean to the western Pacific. These are accompanied by circulation anomalies that are global in extent. The MJO affects monsoon systems across the tropics, impacts on extratropical weather regimes, and plays a role in the triggering and onset of El Niño events. Comprehensive reviews of the MJO are given by Zhang (2005) and Lau and Waliser (2005).

Analysis of satellite and buoy measurements of sea surface temperature (SST) have revealed a coherent MJO cycle in the upper ocean, in quadrature with the MJO surface flux anomalies. Warm SST anomalies follow the calm, cloud-free, dry phase of the MJO, with its increase in downward surface shortwave radiation and reduction in evaporation and upward latent heat flux. Similarly, cold SST anomalies follow the windy, cloudy, wet phase of the MJO (Flatau et al. 1997; Shinoda et al. 1998, 1999; Woolnough et al. 2000; McPhaden 2002). The observed MJO SST anomalies are largely reproducible as the response to the observed MJO surface flux anomalies in one-dimensional (vertical) thermodynamic mixed layer models (e.g., Shinoda and Hendon 1998; Batstone et al. 2005), although zonal advection is also important in the Pacific (Shinoda and Hendon 2001). 
The phase relationship between the MJO SST and convective anomalies is also consistent with the ocean forcing the atmosphere, as warm SST anomalies lead the active convective phase of the MJO by a quarter cycle. Atmospheric models forced with intraseasonal SST anomalies can partly reproduce the MJO convective signal (Woolnough et al. 2001; Matthews 2004; Fu and Wang 2004) but there are issues with the time lag of the atmospheric response. Nonetheless, there may be a role for ocean-atmosphere coupling within the MJO. The simulation of the MJO in some coupled oceanatmosphere models has improved when compared with that in the atmosphere-only version (e.g., Inness and Slingo 2003), but this improvement is not universal (Hendon 2000). Hence, one possible paradigm is that the MJO can exist independently as an atmosphereonly phenomenon, but that it becomes stronger and more coherent when ocean-atmosphere coupling is included.

The dynamical response of the ocean to the MJO is also significant, with oceanic equatorial Kelvin waves in the Pacific being forced by MJO wind stress anomalies (Kessler et al. 1995; Hendon et al. 1998; Zhang 2001). These Kelvin waves can then be instrumental in triggering El Niño events (McPhaden 1999, 2002; Kessler and Kleeman 2000; Kutsuwada and McPhaden 2002; Zhang and Gottschalk 2002; Seo and Xue 2005). These analyses were mainly carried out using data from the TOGATAO array of moored buoys, that cover the equatorial Pacific, and measure temperature down to $500 \mathrm{~m}$. Until recently, there were no deeper temperature data suitable for such large-scale analysis of intraseasonal variability, and no suitable salinity data at any depth, except from single isolated buoys (Cronin and McPhaden 1998). Some studies have found intraseasonal signals in the deep tropical ocean (e.g. Heywood et al. 1994), but these have been limited to local, short term measurements.

However, the amount of deep-ocean data on intraseasonal time scales has increased by at least an order of magnitude with the deployment of Argo floats from 2000 onwards (Gould et al. 2004; Alverson and Baker 2006). Each float drifts at a parking depth (normally at $1000 \mathrm{~m}$ ), and then every 10 days it descends to a base level (normally at $2000 \mathrm{~m}$ ) and then ascends to the surface, measuring a profile of temperature and salinity as it rises. At the surface, the data are sent via satellite, then the float automatically descends back to its parking depth. The 10-day repeat cycle and large number of floats are now providing the oceanographic community with unprecedented high spatial and temporal resolution data of the upper 1000-2000 $\mathrm{m}$ of the world oceans.
Applications of Argo data have included analysis of ocean Rossby waves (Chu et al. 2007) and deep seasonal temperature variations (Hosoda et al. 2006). Recently, the high temporal resolution of the Argo data was used to show that the temperature structure of an equatorial Kelvin wave in the Pacific, forced by a particular MJO event, extended down to at least $1500 \mathrm{~m}$ depth (Matthews et al. 2007), deeper than expected from theoretical considerations (Johnson and McPhaden 1993).

In this paper, we present the three-dimensional structure of oceanic temperature and salinity anomalies throughout a composite MJO cycle, using gridded Argo data from the Indian and Pacific Oceans. These are discussed in the light of existing observational and theoretical studies.

\section{Data and methodology}

\subsection{Argo data}

The first floats of the Argo programme were deployed in 2000 , and now number over 3000 . However, spatial coverage of the tropical Indian and Pacific Oceans was not sufficient to study intraseasonal variability until 2003. This study uses 4 years of Argo data, from 1 January 2003 to 31 December 2006. The Argo float profiles were extracted from the real-time quality controlled Argo data base at http://www.argo.ucsd.edu. Only profiles flagged as "good" were used. Each profile had a latitude and longitude location, and temperature and salinity measurements (accurate to $0.005^{\circ} \mathrm{C}$ and 0.01 , respectively) at non-standard pressure levels. Temperature data from each Argo float profile were then interpolated onto standard pressure levels every 5 dbar, from 5 dbar to 2000 dbar.

A four-dimensional Cartesian grid was created, with a horizontal resolution of $1^{\circ}$ longitude $\times 1^{\circ}$ latitude, a vertical resolution of $5 \mathrm{dbar}$, and a time resolution of 7 days. For a given target grid point at longitude, latitude $\left(x_{0}, y_{0}\right)$ at a given target time, a search ellipse was constructed, centred on the target grid point, with a semi-major axis of $4 L_{x}$, where $L_{x}=1000 \mathrm{~km}$ in the zonal $(x)$ direction, and a semi-minor axis of $4 L_{y}$, where $y_{0}=250 \mathrm{~km}$ in the meridional $(y)$ direction. All available Argo temperature measurements within the search ellipse, on the same level, and within a 7-day search window centred on the target time, were then used to construct the gridded temperature value $\bar{T}$,

$\bar{T}\left(x_{0}, y_{0}\right)=\frac{\sum_{i=1}^{n} w_{i} T_{i}}{\sum_{i=1}^{n} w_{i}}$, 
with the observations being Gaussian-weighted by their horizontal distance from the target grid point,

$w_{i}=\exp \left\{-\left[\left(\frac{x_{i}-x_{0}}{L_{x}}\right)^{2}+\left(\frac{y_{i}-y_{0}}{L_{y}}\right)^{2}\right]\right\}$,

where $n$ is the number of Argo observations within the search ellipse, $T_{i}$ is the temperature value of the $i$ th observation, and $x_{i}$ and $y_{i}$ are the $x$ and $y$ coordinates of the $i$ th observation. Hence, the relative weightings decreased from 1 at the target grid point to $e^{-4} \approx 0.02$ at the boundary of the search ellipse. If there were $n<3$ observations within a search ellipse, the gridded value $\bar{T}$ was flagged as missing, and no numerical value was calculated. To interpolate over occasional missing values, a smooth curve was fitted through the time series of temperature at each grid point. The actual temperature values were retained where they existed, but missing values were replaced by values from the fitted curve. If there were greater than three consecutive missing values (weeks), then the whole time series at that grid point was set to missing. The choice of values for $L_{x}$ and $L_{y}$ are consistent with gridding of other oceanographic data sets (Meyers et al. 1991; Reynolds and Smith 1994; Kessler et al. 1996) and are appropriate to capture the spatial scales of variability in the tropical oceans. Salinity was gridded in a similar way. Potential temperature was then calculated from temperature, salinity and pressure.

For each grid point, the mean and first two annual harmonics of the time series were calculated over the four-year period 2003-06 and subtracted to produce an anomaly time series. The interannual variability was then removed by subtracting an 11-week running mean. Dynamic height and geostrophic current fields were calculated from the gridded Argo temperature and salinity data. The reference level of zero dynamic height anomaly and current speed was taken to be 950 dbar, the deepest level at which there was adequate data coverage.

\subsection{Subsidiary data}

Further data sets were used to provide information on the MJO, and to validate the Argo data. The gridded outgoing longwave radiation (OLR) data set of Liebmann and Smith (1996) was used as a proxy for deep tropical convection. Gridded 1000-hPa wind, surface latent heat flux and precipitation rate fields were extracted from the NCEP-NCAR reanalysis (Kalnay et al. 1996). These data were all daily means, on $2.5^{\circ}$ longitude $\times 2.5^{\circ}$ latitude grids. The weekly mean NOAA optimally interpolated sea surface temperature V2 data set (Reynolds et al. 2002) was used to validate the Argo data. The 5-day mean fields of the depth of the $20^{\circ} \mathrm{C}$ isotherm in the tropical Pacific from the TAO buoy network were also used to validate the Argo data set. Only data for the study period 2003-06 were used, to be consistent with the relatively short Argo data set. The mean and first two harmonics of the annual cycle were calculated over the 4-year period 2003-2006 and subtracted to produce anomaly fields. A 7-day running mean was then applied to the daily OLR and reanalysis data.

\subsection{Validation of Argo data}

An equatorial longitude--depth section of the time-mean gridded Argo potential temperature field (Fig. 1a) reproduces the climatological features of the Indian and Pacific Oceans, and is in excellent quantitative agreement with climatologies constructed from much longer data sets, such as the 2005 World Ocean Atlas (Locarnini et al. 2006; Antonov et al. 2006) and the TAO buoy data for the Pacific (Yu and McPhaden 1998). The surface warm pool over the Indian Ocean and western Pacific, the surface cold tongue in the eastern Pacific, the sloping thermocline, and the cooler abyssal waters are all represented accurately. Similarly, the mean Argo gridded salinity (Fig. 1b) also reproduces the mean climatological features: the fresh surface warm pool over the eastern Indian Ocean and western Pacific, the saline surface waters in the central Pacific, the fresh eastern Pacific, and the subsurface salinity maximum along the thermocline in the Pacific, with fresher waters below. Again, these are all in excellent quantitative agreement with the 2005 World Ocean Atlas. These Argo climatological temperature and salinity fields will be used to interpret the intraseasonal anomalies later.

The more demanding question of whether the gridded Argo data can resolve intraseasonal features is now addressed. For validation, a Hovmöller diagram of equatorial thermocline depth (depth of the $20^{\circ} \mathrm{C}$ isotherm; D20) anomalies from the Pacific TAO buoy array is shown in Fig. 2b. Eastward-propagating intraseasonal anomalies can clearly be seen over the whole four-year period. These have an average phase speed of approximately $2.2 \mathrm{~m} \mathrm{~s}^{-1}$, and are diagnostic of equatorial Kelvin waves with a first internal mode vertical structure (e.g., Kessler et al., 1995). Individual MJO events are shown by the eastward-propagating equatorial OLR anomalies (hatched). Active MJO events (enhanced convection, negative OLR anomalies) can be seen to force downwelling equatorial Kelvin waves (positive D20 anomalies) on many occasions; 14 such events are marked by thick diagonal lines in Fig. 2b. This behaviour is 
consistent with previous studies of MJO-forced oceanic Kelvin waves (Kessler et al., 1995; Hendon et al., 1998; Zhang, 2001).

The comparable Hovmöller diagram from the gridded Argo data set is shown in Fig. 2a. The Argo data reproduces the intraseasonal variability seen in the TAO data to a high degree of accuracy. In particular, the timings, phase speeds and amplitudes of the equatorial Kelvin waves are in excellent agreement. Hence, this validation against the reliable TAO data in the upper ocean increases our confidence in the fidelity of the Argo data in the deeper ocean, where there are no other data sets with this high degree of both temporal and spatial resolution.

\subsection{MJO definition and compositing}

We use the real-time multivariate MJO (RMM) index of Wheeler and Hendon (2004) to define the MJO. This index is comprised of two daily time series, denoted RMM1 and RMM2. These are the principal-component time series of the first two EOFs of combined nearequatorially averaged OLR, and 200 and 850-hPa zonal winds. The indices are available in real time and used to operationally monitor and forecast the state of the MJO. The RMM1 and RMM2 daily time series were extracted for the study period 2003-06, and then averaged into 7-day means to be consistent with the Argo and other data used here.

Following Wheeler and Hendon (2004), the 208 pairs of (RMM1,RMM2) values, one for each 7-day mean within the study period, are shown in the (RMM1,RMM2) phase-space diagram of Fig. 3. The diagram is divided into 8 regions, labelled MJO phases 1 to 8 , that depend on the relative amplitudes of RMM1 and RMM2. The path formed by tracing forward in time through the (RMM1,RMM2) points tends to move in an anticlockwise direction around the origin (not shown). Hence, the MJO progresses from phase 1 through to 8 , then round again. The central circle, with a radius of 1 , denotes the region of weak MJO activity. Those weeks whose (RMM1,RMM2) values fall within this circle were excluded from the subsequent MJO analysis.

Composite mean anomalies for a particular MJO phase were created by averaging together the data for all the weeks whose (RMM1,RMM2) values lie within the relevant region in the phase-space diagram. For example, the OLR anomaly maps from the $N=18$ weeks that lie in the phase 1 region of Fig. 3 are averaged together to produce the composite mean for phase 1 of the MJO (Fig. 4a).

The statistical significance of these anomalies at each grid point is determined by a Student's $t$-test. Care needs to be taken, as this test assumes that all $N$ samples that contribute to the mean are independent. On average, a single MJO event lasts 44 days (Matthews 2008). Hence, the average time spent in each of the 8 phases is $44 / 8=5.5$ days, which is less than the 7 -day time interval of the data. Therefore, subsequent weeks tend to be in different phases. However, very occasionally two consecutive weeks lie in the same MJO phase. When this happens, the anomaly fields from those two weeks are first averaged together into a single anomaly field, which is then input into the composite mean process. This ensures that all $N$ samples that are used to create the composite mean are from different MJO events and are independent. Hence, the $t$-test can be applied. There are $N=18,13,11,10,20,11,12$, and 14 independent events in phases $1-8$, respectively.

\section{Composite atmospheric MJO cycle}

During phase 1 (Fig. 4a), the negative OLR anomalies over the western Indian Ocean indicate the enhanced convection at the start of the MJO cycle. The positive OLR anomalies over the maritime continent and the western Pacific indicate suppressed convection there, in the other half of the well-known MJO convective dipole pattern. By phase 2 (Fig. 4b), the dipole pattern has moved eastward, with enhanced convection over the eastern Indian Ocean, and suppressed conditions over the western Pacific. In phases 3 and 4 (Fig. 4c,d) the enhanced convection continues eastward through the maritime continent, while the area of suppressed convection diminishes. A new region of suppressed convection appears over the western Indian Ocean in phase 5 (Fig. 4e), while it is the turn of the enhanced convection to diminish over the central Pacific. By phase 8 (Fig. 4h), there are suppressed conditions over most of the warm pool.

The OLR features in Fig. 4 are calculated using just the 4 years of data (2003-06) for which the Argo data were also available in sufficient quantity. The MJO cycle in OLR is very similar to one calculated using 17 years of data (1990-2006; not shown) and to many other previous studies using longer data sets (e.g., Matthews 2000; Wheeler and Hendon 2004). Hence, the short period over which the Argo data are available is long enough to create a robust composite of the MJO. 
4 Oceanographic surface structure of $\mathrm{MJO}$ and atmospheric thermodynamic forcing

\subsection{Temperature}

The (near) surface ocean conditions during the MJO are now examined using the Argo data. Strictly speaking, there is not a sea surface temperature field in the gridded data set. The shallowest level from the gridded data is at a pressure level of 5 dbar, corresponding to a depth of $5 \mathrm{~m} .{ }^{1}$ However, there were many missing data at this level, as the highest record from many individual Argo float profiles was below 5 dbar. Hence, the composite cycle of Argo temperature anomalies at 10 dbar (the next level) is shown in Fig. 5. Composites of the 5 dbar Argo temperature anomalies were very similar, where they existed. As the Argo floats drift at a depth of around $1000 \mathrm{~m}$, they cannot penetrate into the shallow seas that surround the maritime continent. Hence, there are missing data in this region and elsewhere, shown by the black shading in Fig. 5 .

During phase 1 of the MJO, there are statistically significant positive 10 dbar Argo temperature anomalies over much of the warm pool, particularly over the eastern Indian Ocean (Fig. 5a). At this phase, the enhanced deep cloud cover over the western Indian Ocean (negative OLR anomalies in Fig. 4a) reflects more incident solar radiation, reducing the surface shortwave radiation flux. This leads to negative 10 dbar Argo temperature anomalies there, by phase 2 (Fig. 5b), consistent with previous studies (e.g., Shinoda et al. 1998, 1999; Woolnough et al. 2000). As the MJO over the Indian Ocean develops further in phase 3, surface (1000$\mathrm{hPa}$ ) westerly wind anomalies form (Fig. 4c), as the part of the atmospheric equatorial Rossby wave response to the enhanced convection (Hendon and Salby 1996; Matthews et al. 2004). These wind anomalies are aligned with the mean westerly winds over the Indian Ocean. Hence, the total surface wind speed and the surface latent heat flux increase. This enhanced cooling of the ocean, together with the reduction in surface shortwave radiation from the increased cloudiness, leads to the strong negative Argo 10 dbar anomalies in phase 4 (Fig. 5d).

During the second half of the MJO cycle, the anomalies reverse. Positive OLR anomalies over the Indian Ocean from phase 5 onwards (Fig. 4e) indicate reduced cloudiness and increased surface shortwave radiation flux. There are surface easterly anomalies from phase 7

\footnotetext{
1 A pressure increase of 1 dbar corresponds to a depth increase very close to $1 \mathrm{~m}$. All calculations were made on pressure surfaces. For simplicity, these are sometimes reported as (nominal) depths, assuming that $1 \mathrm{~m} \equiv 1 \mathrm{dbar}$.
}

(Fig. 4g), as part of the atmospheric equatorial Rossby wave response to the reduced convective heating. These are in the opposite direction to the mean winds. They reduce the total wind speed, and the latent heat flux, leading to the positive Argo 10 dbar temperature anomalies in phase 8 (Fig. 5h).

Over the western Pacific, the implied changes in the surface shortwave radiation and latent heat fluxes are also consistent with the observed changes in the Argo 10 dbar temperatures. In phases 1 and 2, the positive OLR anomalies (Fig. 4a,b) are associated with an increase in the shortwave flux, leading to the strong warm Argo 10 dbar temperature anomalies there in phase 3 (Fig. 5c). In phases 3 and 4, the atmospheric equatorial Kelvin wave response to the enhanced MJO convection over the Indian Ocean generates surface easterly anomalies over the western Pacific (Fig. 4c,d). These are in the same direction as the mean easterlies there, increasing the total wind speed and latent heat flux. This cools the ocean surface, leading to the negative Argo 10 dbar temperature anomalies in the western Pacific in phases 5 and 6 (Fig. 5e,f). These are then reinforced by the reduction in shortwave radiation as the MJO enhanced convection moves eastward into the western Pacific (Fig. 4e,f).

In the eastern Pacific, the OLR and surface wind anomalies are weak. Hence, the large Argo 10 dbar temperature anomalies observed there (Fig. 5) cannot be just a thermodynamical response to surface flux anomalies. These are discussed later, in section 5 , in terms of dynamical forcing.

The Argo 10 dbar temperature composites were calculated from just 4 years of data (2003-06) and are comparable to composites of NOAA OI v2 sea surface temperature anomalies, calculated over the same period. For example, the NOAA SST composites at phases 4 and 8 (Fig. 6) are very similar to their Argo 10 dbar temperature counterparts in Fig. 5e,h. Previous studies (e.g., Shinoda et al. 1998; Woolnough et al. 2000; Shinoda and Hendon 2001) have shown that the NOAA data can be used to reliably diagnose the surface oceanic component of the MJO. The two sets of composites (Figs. 5 and 6) are qualitatively very similar. Hence, the four years of Argo data are of sufficiently high quality and quantity to represent the surface MJO features. This gives us further confidence in our later interpretation of the subsurface MJO structure using the Argo data.

\subsection{Salinity}

The oceanic salinity cycle of the MJO is now presented, for the first time. Large-scale, coherent, statistically 
significant, 10 dbar ("surface") salinity anomalies are present throughout the Indian and Pacific Oceans, in all phases of the MJO (Fig. 7). These salinity anomalies are large amplitude, with peak values near 0.05 , comparable to the amplitude of the annual cycle. Surface salinity in the mixed layer can be changed by the net evaporation minus precipitation $(E-P)$ flux and horizontal advection (Cronin and McPhaden 1998). Hence, composite $E-P$ anomalies are shown in Fig. 8. The role of advection is discussed in section 5 .

In phase 1 of the MJO there are no statistically significant surface salinity anomalies in the equatorial Indian Ocean (Fig. 7a). However, there are negative OLR anomalies over the central Indian Ocean (Fig. 4a), which are associated with enhanced precipitation and a negative (freshening) $E-P$ flux (Fig. 8a). As these OLR anomalies develop and move eastward (Fig. 4b,c) they lead to the significant, negative salinity anomalies that cover the central and eastern Indian Ocean in phases 2 and 3 (Fig. 7b,c). Note that in phase 3, for example, while the active MJO has increased precipitation, this is partially offset by increased evaporation, as the surface westerly wind anomalies are in phase with the climatological westerlies there, increasing the total wind speed. However, the changes in precipitation are larger than those in evaporation, leading to a negative $E-P$ anomaly. In the second half of the MJO cycle (phases 5-8), the opposite occurs, with the dry (inactive) phase of the MJO in the Indian Ocean (Fig. 4e-h) leading to positive $E-P$ anomalies (Fig. $8 \mathrm{e}-\mathrm{h}$ ) and positive salinity anomalies there (Fig. 7e-h).

The quantitative effect of the $E-P$ flux anomalies on the surface salinity can be calculated approximately by a scale analysis. Assuming an $E-P$ anomaly of $\sim 1 \mathrm{~mm} \mathrm{day}^{-1}$ (Fig. 8b,c) acting for two MJO phases ( $\sim 12$ day) gives a precipitation excess of $\sim 12 \mathrm{~mm}$. Adding this to a mixed layer of depth $\sim 50$ m leads to a fractional change in salinity of $\sim 2.5 \times 10^{-4}$. Assuming a salinity of $\sim 35$, this leads to a salinity anomaly of $\sim 0.01$, which is the same order as the salinity anomalies in Fig. 7. Hence, the MJO surface salinity anomalies in the Indian Ocean can be semi-quantitatively explained as a response to the MJO $E-P$ anomalies.

This is not the case in the western Pacific. During MJO phases 1 and 2, the $E-P$ anomalies over the western Pacific are positive (Fig. 8a,b), giving a positive salinity tendency. However, the salinity anomalies that develop, in phase 3, are negative. Similarly, in the opposite half of the cycle, the negative, freshening $E-P$ anomalies that cover the western Pacific during phases 3-5 (Fig. 8c-e) are followed by positive salinity anomalies in phases $4-6$ (Fig. $7 \mathrm{~d}-\mathrm{f})$. Hence, another process must be responsible for the salinity anomalies in the western Pacific, and also the central and eastern Pacific. In section 5 , it is shown that they can be partly explained by horizontal advection.

The relative importance of the near-surface temperature and salinity anomalies to the density structure of the ocean can be estimated. For example, in MJO phase 8 , there are positive 10 -m temperature anomalies of $\Delta T \approx 0.1{ }^{\circ} \mathrm{C}$ across the tropical Indian Ocean (Fig. 5h). These lead to a decrease in density of $\Delta \rho \approx$ $-0.03 \mathrm{~kg} \mathrm{~m}^{-3}$, using the equation of state for sea water with a parcel at $T=28^{\circ} \mathrm{C}$ and $S=35$. These are accompanied by positive salinity anomalies of $\Delta S \approx$ 0.02 (Fig. $7 \mathrm{~h}$ ) which lead to an increase in density of $\Delta \rho \approx 0.015 \mathrm{~kg} \mathrm{~m}^{-3}$. The density effect from the salinity anomalies is approximately half that from the temperature anomalies, and offsets it. Hence, modelling of the thermodynamic structure of the upper ocean in the MJO needs to take account of both temperature and salinity changes.

\section{Dynamical forcing of the oceanic MJO in the Pacific}

Thermodynamic forcing alone is not sufficient to explain much of the surface (10 dbar) temperature and salinity structure of the MJO in the Pacific. Here, we look at the role of dynamical processes, particularly equatorial waves.

\subsection{Thermocline}

The Argo gridded data have been shown to accurately resolve the individual equatorial Kelvin waves forced by the MJO over the four-year study period (Fig. 2). The average MJO cycle in thermocline depth is shown in a composite Hovmöller diagram (Fig. 9a) where time is lagged relative to phase 1 of the MJO, when the active convection is beginning over the Indian Ocean. Clear eastward propagation can be seen right across the Pacific. Negative D20 anomalies, corresponding to an upward displacement of the thermocline, start in the western Pacific around lag 12 days, which corresponds approximately to phase 3 . These are consistent with forcing by westward surface wind stress anomalies (Fig. 4c) and surface Ekman flux divergence along the equator. This negative D20 anomaly then propagates eastward into the central and eastern Pacific with a phase speed of approximately $2.5 \mathrm{~m} \mathrm{~s}^{-1}$ (thick dashed line in Fig. 9a) and an amplitude above $3 \mathrm{~m}$. Similarly, positive D20 anomalies at lag -12 (approximately phase 6) in the western Pacific are consistent with eastward wind stress anomalies in phases 5 and 
6 (Fig. 4e,f). These then also propagate eastward at $2.5 \mathrm{~m} \mathrm{~s}^{-1}$ (thick solid line in Fig. 9). The comparable composite Hovmöller diagram from TAO data (Fig. 9b) is in good agreement with the Argo data.

An alternative longitude--phase diagram can be constructed using the eight MJO phases on the $y$-axis as a surrogate for time (Fig. 10a). If the MJO is assumed to have a period of 48 days ( 6 days between each phase), then an apparent phase speed can be calculated. However, this has a value over $4 \mathrm{~m} \mathrm{~s}^{-1}$, clearly much higher than any of the individual Kelvin waves in Fig. 2. The reason for this discrepancy is not clear, but is an artefact of the analysis method. The MJO and oceanic Kelvin waves are both genuinely broadband phenomena, with individual events having periods between 3060 days and 60-80 days, respectively (McPhaden and Taft 1988). Hence the linear compositing technique used here could tend to emphasise those events where the frequencies overlap, i.e., low-frequency MJOs and highfrequency Kelvin waves. An alternative explanation involves the MJO phase used to reference the analysis. The longitude-time diagram in Fig. 9 is referenced to a particular phase (phase 1) of the MJO, which can be considered as an impulsive burst of convection and wind stress forcing. The lagged thermocline response to this takes the form of free Kelvin waves, which propagate at their free phase speed of $2.5 \mathrm{~m} \mathrm{~s}^{-1}$. The longitudephase diagram (Fig. 10a) has no particular reference phase, and will emphasise the forced response at each phase of the MJO. As the forcing (OLR and wind stress anomalies) moves eastward at $4-5 \mathrm{~m} \mathrm{~s}^{-1}$, it is perhaps not surprising that the response propagates at a similar speed. Hence, for the purpose of calculating accurate phase speeds, actual time is the preferred dimension to use. This is not without its problems though. Because of the wide range of life times of individual events (typically between 30 and 60 days, up to a factor of 2 different), the composite signal attenuates at large lags (Fig. 9), as MJO events of different periods begin to destructively interfere. The analysis is also biased to the chosen reference phase of the MJO (phase 1 in Fig. 9). Hence, for an unbiased, robust picture of the complete MJO cycle, when accurate phase speeds are not required, the phase-based approach is still preferred (e.g., Figs. 4, 5, 10).

A consistency check on the Kelvin wave structure can be made from a latitudinal section through the temperature anomalies. At $170{ }^{\circ} \mathrm{W}$ in MJO phase 5, there are large negative temperature anomalies in the equatorial thermocline region (Fig. 11), with largest amplitude on the equator. The theoretical wave has a Gaussian structure centred on the equator, $e^{-\beta y^{2} / 2 c}$, where $y$ is distance northward from the equator, and $\beta=2.3 \times 10^{-11} \mathrm{~m}^{-1} \mathrm{~s}^{-1}$ is the latitudinal gradient of planetary vorticity. The latitudinal trapping scale $y_{0}=(2 c / \beta)^{1 / 2}$ is estimated from Fig. 11 as approximately 4 degrees latitude, or $4 \times 10^{5} \mathrm{~m}$. This implies a phase speed of $c \approx 2 \mathrm{~m} \mathrm{~s}^{-1}$, in agreement with the measured phase speed of $c=2.5 \mathrm{~m} \mathrm{~s}^{-1}$. The extension of the equatorially trapped anomaly in the thermocline, downwards into the deep ocean, is discussed in section 5.2 .

The surface dynamic height anomalies associated with these thermocline displacements are shown in Fig. 12. The negative D20 anomaly (upward displacement of the thermocline) in the equatorial western Pacific in phase 3 is mirrored by a negative surface dynamic height anomaly (downward displacement of the surface) above (Fig. 12c). This moves slowly eastward into the central Pacific as a coherent, zonally elongated anomaly with a clear trough (amplitude $0.35 \mathrm{~m}$ ) along the equator by phase 5 (Fig. 12e). By phase 7 (Fig. 12g), it has reached the eastern Pacific, while a positive dynamic height anomaly has appeared in the western Pacific. This then also propagates eastward to the central Pacific by phase 1 (Fig. 12a).

The zonal geostrophic current velocities calculated from the dynamic height are shown in Fig. 13. Eastward (westward) geostrophic currents are clearly colocated with positive (negative) equatorial dynamic height anomalies. These dynamic anomalies are consistent with oceanic first internal mode, baroclinic equatorial Kelvin waves forced by MJO surface wind stress anomalies, as previously diagnosed from TAO buoy data (Johnson and McPhaden 1993; Cravatte et al. 2003; Roundy and Kiladis 2006).

We can now consider the Pacific temperature and salinity anomalies in terms of horizontal advection by these waves. The salinity tendency due to zonal advection is $\partial S / \partial t=-u \partial \bar{S} / \partial x$. For example, taking $u \sim$ $-5 \mathrm{~cm} \mathrm{~s}^{-1}$ in the equatorial western Pacific over the 18 day period during phases 3-5 (Fig. 13c-e), and a mean salinity gradient of $\partial \bar{S} / \partial x \sim 3 \times 10^{-7} \mathrm{~m}^{-1}$ between the fresh waters of the far western Pacific and the more saline waters further east (Fig. 1b), then the salinity change due to advection is $\sim 0.02$, which is of the same sign and comparable magnitude to the observed surface salinity anomalies in the equatorial western Pacific during phase 5 (Fig. 7e). Similar calculations using the mean temperature field in Fig. 1a show that many of the surface temperature anomalies in the central and eastern Pacific (Fig. 5) can also be semi-quantitatively accounted for by horizontal zonal advection. 


\subsection{Deep ocean MJO}

Previous studies of the subsurface oceanic component of the MJO have been mainly limited to the temperature data from the TAO buoys in the equatorial Pacific, down to a depth of $500 \mathrm{~m}$ (e.g., Roundy and Kiladis 2006). The Argo data cover the world oceans to a depth of 1000-2000 m. The deep ocean temperature structure of an individual MJO event in the Pacific was described by Matthews et al. (2007). Here, the canonical deep ocean MJO temperature and salinity cycles are presented for the first time.

\subsubsection{Temperature}

There are large-scale, coherent, statistically significant, MJO temperature anomalies in the deep ocean throughout the tropical Pacific. For example, in phase 8 there are warm (cold) anomalies at 950 dbar in the central (eastern) Pacific (Fig. 14). The available Argo observations only extend down to around 1000 dbar in the eastern Pacific, so 950 dbar was chosen as the deepest level at which there is satisfactory coverage. There are similarly sized 950-dbar temperature anomalies in all other phases of the MJO. These are summarised in a Hovmöller diagram of equatorial 950-dbar temperature anomalies (Fig. 10b). Eastward propagation can clearly be seen.

These deep propagating anomalies can be compared with those propagating at the thermocline level. Note that temperature anomalies at a fixed level between approximately 50 and 150 dbar show similar behaviour to the D20 diagnostic; positive (negative) D20 anomalies correspond to downwelling (upwelling) and positive (negative) temperature anomalies. The deep anomalies lead the thermocline anomalies, and propagate at the same speed as them. For example, the axis of coldest 950-dbar temperature anomalies precedes the axis of minimum D20 anomalies (thick dashed lines in Fig. 10) by 1 MJO phase, or approximately 6 days.

The full vertical structure of the temperature anomalies can be seen in the longitude-depth sections along the equator (Fig. 15); note the expanded depth axis in the upper 200 dbar. Significant temperature anomalies fill the entire Pacific basin down to 1000 dbar. The largest anomalies $\left(\sim 1^{\circ} \mathrm{C}\right)$ are in the thermocline, where the vertical temperature stratification is largest. Although the anomalies decrease in magnitude with depth $\left(\sim 0.1{ }^{\circ} \mathrm{C}\right.$ at $600 \mathrm{dbar}, \sim 0.05{ }^{\circ} \mathrm{C}$ at $\left.900 \mathrm{dbar}\right)$, they are still large as they are comparable to the amplitude of the seasonal cycle $\left(\sim 0.08{ }^{\circ} \mathrm{C}\right.$ at $600 \mathrm{dbar}$, $\sim 0.07{ }^{\circ} \mathrm{C}$ at $\left.900 \mathrm{dbar}\right)$. Individual MJO events can have much larger temperature anomalies; for example, the event of December 2003 to February 2004 included temperature anomalies up to $0.45^{\circ} \mathrm{C}$ at 600 dbar depth (Matthews et al. 2007).

The vertical coherence of the temperature anomalies from the thermocline downwards (Fig. 15) suggests that the equatorial Kelvin wave extends downward into the deep ocean. The 950-dbar anomalies (Fig. 10b) leading those on the thermocline (Fig. 10a) is reflected by the vertical tilt (eastward with increasing depth) of the anomalies in the longitude-depth section This is particularly apparent in the central and eastern Pacific during phases 2 and 4-8 (Fig. 15). The vertical wavelength is estimated to be of the order of $800 \mathrm{~m}$. This tilt is equivalent to a vertical tilt in the phase lines of the wave. The sense of the tilt is one of eastward and upward phase propagation. For an equatorial Kelvin wave, this implies eastward and downward group velocity and energy propagation (Gill 1982; Kessler and McCreary 1993). This is consistent with the forcing of the Kelvin wave from the surface, by the MJO wind stress anomalies. However, there does not appear to be uniform downward propagation. Below about $800 \mathrm{~m}$ depth, the anomaly contours (phase lines of the wave) tend to become more vertical (e.g., in MJO phase 6 at $120^{\circ} \mathrm{W}$; Fig. $\left.15 \mathrm{f}\right)$.

Vertically propagating equatorial waves obey the dispersion relation $c=N / m$, where $c$ is the phase speed, $N$ is the buoyancy frequency and $m$ is the vertical wavenumber (Gill, 1982). The mean density stratification was calculated from the Argo temperature and salinity data and gave $N \approx 0.017 \mathrm{~s}^{-1}$ in the thermocline. Using the observed phase speed of $c=2.5 \mathrm{~m} \mathrm{~s}^{-1}$, the theoretical vertical wavenumber is $m=7 \times 10^{-3} \mathrm{~m}^{-1}$ and the corresponding vertical wavelength is $2 \pi / m=$ $900 \mathrm{~m}$, consistent with the estimated observed vertical wavelength of $800 \mathrm{~m}$. However, the stratification weakens considerably with depth to around $N \approx 4 \times 10^{-3} \mathrm{~s}^{-1}$ at a depth of $500 \mathrm{~m}$, with a correspondingly much larger vertical wavelength of approximately $4000 \mathrm{~m}$. Hence, the vertical wavelength would be expected to increase with depth, with the consequence that phase lines would tilt back towards the vertical. This is consistent with the structures described above.

An alternative interpretation to these locally vertically propagating waves, is to consider the observed structures as the superposition of several vertical modes: the eigen modes of the vertical structure equation using the observed background stratification. However, the effect of the mean flow also needs to be taken into account. Using the observed Pacific background state with both stratification and mean currents, Johnson and McPhaden (1993) showed that the higher order vertical modes (mode 3 and above) are dissipated in 
a critical layer due to the equatorial undercurrent. The deep structure in their model was consistent with the first baroclinic mode, modified by wave-mean flow interactions.

Hence, from these temperature composites, there is good evidence that a deep ocean equatorial Kelvin wave response should be added to the canonical view of the MJO.

\subsubsection{Salinity}

The deep salinity structure of the MJO is now examined in the equatorial Kelvin wave framework. In the Pacific, there are coherent, statistically significant salinity anomalies from the surface all the way down to 1400 dbar, the deepest level of observations (Fig. 16). However, they are slightly more difficult to interpret due to the more complex structure of the mean salinity field compared to temperature. The mean temperature decreases monotonically with depth everywhere in the equatorial Pacific (Fig. 1a). The cold anomalies at, e.g., $160^{\circ} \mathrm{W}$ in phase 6 of the MJO (Fig. 15f) extend continuously from the thermocline down to $1000 \mathrm{dbar}$. These have been interpreted as an upwelling Kelvin wave, bringing up colder water from deeper down at each level. The cold anomalies in the mixed layer at $160^{\circ} \mathrm{W}$, phase 6 are due to westward horizontal advection (Fig. 13f) of the colder water that lies to the east (Fig. 1a). The same dynamical processes operate on the salinity field. However, the mean vertical profile of salinity is not monotonic (Fig. 1b). It is relatively fresh at the surface (albeit with very strong horizontal gradients), increases to a salinity maximum near the thermocline, then becomes fresher with depth. At $160^{\circ} \mathrm{W}$, phase 6 (Fig. 16f), the negative salinity anomalies below 100 dbar are due to the upwelling of fresher water from below. Above the mean salinity maximum at 100 dbar, the thin layer of positive salinity anomalies are still due to upwelling, but of more saline water. Again, in the mixed layer, the (negative) salinity anomalies are due to westward horizontal advection of the fresher water that lies to the east (Fig. 1b).

Note that the deeper salinity anomalies below about 600 dbar are not as coherent as their respective temperature anomalies. This is due to the mean vertical salinity gradients being very weak at depth (Fig. 1b). Hence, any vertical motion will advect water of only slightly different salinity to any given level, leading to a small amplitude anomaly. Nonetheless, under the assumption that the subsurface temperature and salinity anomalies are due to vertical advection, in the upwelling and downwelling parts of a Kelvin wave, the implied vertical displacement $\Delta z$ can be calculated from the temperature and salinity fields independently:

$$
\Delta z_{\theta}=-\frac{\theta^{\prime}}{\partial \bar{\theta} / \partial z}, \quad \Delta z_{S}=-\frac{S^{\prime}}{\partial \bar{S} / \partial z},
$$

where $\Delta z_{\theta}$ and $\Delta z_{S}$ are the displacements calculated from the potential temperature and salinity fields, $\theta^{\prime}$ and $S^{\prime}$ are the potential temperature and salinity anomalies, and $\partial \bar{\theta} / \partial z$ and $\partial \bar{S} / \partial z$ are the mean vertical potential temperature and salinity gradients, respectively.

For example, in MJO phase 8, the two displacement fields (Fig. 17) are broadly consistent, in and below the thermocline. There are negative, downward displacements in the central Pacific, and positive, upward displacements in the eastern Pacific. These displacements have large amplitude, above $8 \mathrm{~m}$ right down to the 1400 dbar level. The two displacement fields are neither consistent nor valid above the thermocline, as surface fluxes and horizontal advection have a greater effect than vertical advection on the temperature and salinity anomalies there.

\section{Dynamical forcing of the oceanic MJO in the Indian Ocean}

The Indian Ocean also responds to dynamical forcing from the MJO, although the details of the response are less clear here than they are for the Pacific. For example, during MJO phase 3 there are westerly surface wind anomalies over the central equatorial Indian Ocean (Fig. 4c). These lead to a deepening of the equatorial thermocline (positive D20 anomalies in Fig. 10a), a raising of the surface (positive surface dynamic height anomalies in Fig. 12c) and associated eastward surface geostrophic current anomalies (Fig. 13c). These anomalies are consistent with an equatorial Kelvin wave packet in the central Indian Ocean. Simultaneously, the raised thermocline in the eastern Indian Ocean (negative D20 anomalies at phase 3 in Fig. 10a) is consistent with a dynamic response to the easterly surface wind anomalies there in the previous two MJO phases (Fig. 4a,b). By phase 6, the positive equatorial D20 anomalies have moved eastward from the central to the eastern Indian Ocean (Fig. 10a), but continuous eastward propagation is not apparent. In phase 8 , the easterly wind anomalies over the central Indian Ocean (Fig. 4h) give rise to dynamic anomalies of the opposite sign, with a raised thermocline (Fig. 10a), and negative surface dynamic height (Fig. 12h) and zonal geostrophic current (Fig. 13h) anomalies.

There is evidence of a statistically significant deep ocean response to the MJO in the Indian Ocean. For example, during phase 8 , there are negative 950-dbar 
temperature anomalies in the equatorial Indian Ocean (Fig. 14), below the negative temperature anomalies at the thermocline level. However, the vertical coherence in the Indian Ocean is less than in the Pacific (Fig. 15), although there are times when a coherent anomaly can be detected from the surface down to the deepest level, such as in the eastern Indian Ocean during phase 2 (Fig. 15b).

There are also significant salinity anomalies in the deep Indian Ocean that are coherent with those at the surface. For example, in phase 8 positive salinity anomalies extend from the deepest level at 1400 dbar up to the surface in the central Indian Ocean (Fig. 16h). These are dynamically consistent with the temperature anomalies in the deep ocean, as both variables imply downward displacement there (Fig. 17).

\section{Conclusions}

The recent availability of Argo data has given unprecedented spatial and temporal coverage of the world oceans, allowing a detailed analysis of intraseasonal variability over whole ocean basins for the first time. Here, the MJO has been shown to have a response in the deep Indian and Pacific Oceans, that would not have been detectable with conventional oceanographic data.

The MJO-forced equatorial Kelvin waves that extend down to the deep Pacific have very large amplitude; their geostrophic currents are of the same order of magnitude as those from the mean circulation and annual cycle. As the waves are forced at the surface, their large-amplitude deep structure represents a substantial energy transfer to the deep ocean. This energy must ultimately be dissipated at depth, with implications for ocean mixing. The vertical motion fields of these waves also has an impact on biological productivity in the mixed layer (Waliser et al. 2005). The effect of this at depth can now be investigated.

There is also clear evidence for the existence of a statistically significant temperature and salinity cycle in the MJO in the subsurface and deep Indian Ocean. However, it is less coherent and harder to interpret than that in the Pacific, with the data available here. This is potentially owing to data volume; the Argo float coverage was less in the Indian Ocean than in the Pacific, particularly during the first half of the analysis period in 2003 and 2004. The MJO changes character with the annual cycle over the Indian Ocean more than over the Pacific. During northern winter, the MJO exhibits its canonical equatorial eastward-propagating properties. However, during northern summer, it switches character over the Indian Ocean to contain a significant northward-propagating component. Together with the change in atmospheric and oceanic basic states between the summer and winter monsoons, the ocean dynamical component of the MJO is likely to differ significantly between the seasons. This would have a detrimental effect on the MJO cycle analysed here, which used allyear round data. With only four years of available Argo data, the record was not long enough to analyse winter and summer separately. As a longer data set becomes available, such an analysis could be carried out.

During the 2003-2006 study period, the Pacific basin was mainly in a weak El Niño state. This could potentially have biased the results, as the characteristics of the oceanic equatorial Kelvin waves can change as El Niño events progress (Roundy and Kiladis 2006). Again, once a longer term Argo data set becomes available, this can be investigated.

The deep ocean structure of the MJO could potentially have an influence on the deep ocean circulation. Ocean modelling studies of the MJO (e.g., Han et al. 2001; Shinoda et al. 2008) have focussed on the upper layers; the ability of the ocean and coupled models to simulate the MJO deep structure is not known.

The deep response to the MJO is likely to extend beyond the tropical Indian and Pacific Oceans. The atmospheric MJO has a global structure (Hsu 1996) that can be well simulated in an atmospheric model if the MJO tropical heating pattern is correct (Matthews et al. 2004). This will initiate a response in the extratropical oceans, such as that observed around the Antarctic coast from bottom pressure recorders (Matthews and Meredith 2004). The Argo float network is near-global. An analysis of the global ocean MJO structure using this data source, especially once several years of high coverage become available, should prove to be rewarding.

Acknowledgements These data were collected and made freely available by the International Argo Project and the national programs that contribute to it (http://www.argo.ucsd.edu and http://argo.jcommops.org). Argo is a pilot program of the Global Ocean Observing System. The interpolated OLR, NCEP Reanalysis, and NOAA interpolated sea surface temperature data were provided by the NOAA/OAR/ESRL PSD, Boulder, Colorado, USA, from their web site at http://www.cdc.noaa.gov/. The TAO buoy data were provided by the TAO Project Office of NOAA/PMEL from their web site at http://www.pmel.noaa.gov/tao/index.shtml. The Wheeler and Hendon MJO index data were provided by Matt Wheeler, from the Australian Bureau of Meteorology website at http://www.bom.gov.au/bmrc/clfor/cfstaff/matw/maproom/RMM/index.htm. PS studentship was partially funded by the Thai government. We thank two anonymous reviewers whose comments helped to improve the manuscript. 


\section{References}

Alverson K, Baker DJ (2006) Taking the pulse of the oceans. Science 314: 1657.

Antonov JI, Locarnini RA, Boyer TP, Mishonov AV, Garcia HE (2006) World Ocean Atlas 2005, Volume 2: Salinity. NOAA Atlas NESDIS 62, U.S. Government Printing Office, Washington, D.C..

Batstone CP, Matthews AJ, Stevens DP (2005) Coupled ocean-atmosphere interactions between the Madden Julian oscillation and synoptic-scale variability over the warm pool. J. Climate 18: 2004-2020.

Chu PC, Ivanov LM, Melnichenko OV, Wells NC (2007) On long baroclinic Rossby waves in the tropical North Atlantic observed from profiling floats. J. Geophys. Res. 112: C05032. doi: 10.1029/2006JC003698

Cravatte S, Picaut J, Eldin G (2003) Second and first baroclinic Kelvin modes in the equatorial Pacific at intraseasonal time scales. J. Geophys. Res. 108: 3266. doi: 10.1029/2002JC001511

Cronin MF, McPhaden MJ (1998) Upper ocean salinity balance in the western equatorial Pacific. J. Geophys. Res. 103: 27567-27587.

Flatau M, Flatau PJ, Phoebus P, Niiler PP (1997) The feedback between equatorial convection and local radiative and evaporative processes: The implications for intraseasonal oscillations. J. Atmos. Sci. 54: $2373-2386$.

Fu XH, Wang B (2004) Differences of boreal summer intraseasonal oscillations simulated in an atmosphereocean coupled model and an atmosphere-only model. J. Climate 17: 1263-1271.

Gill AE (1982) Atmosphere-ocean dynamics. Academic Press.

Gould J, Roemmich D, Wijffels S, Freeland H, Ignaszewsky M, Jianping X, Pouliquen S, Desaubies Y, Send U, Radhakrishnan K, Takeuchi K, Kim K, Danchenkov M, Sutton P, King B, Owens B, Riser S (2004) Argo profiling floats bring new era of in situ ocean observations. Eos 85: 179, 190-191.

Han W, Lawrence DM, Webster PJ (2001) Dynamical response of equatorial Indian Ocean to intraseasonal winds: zonal flow. Geophys. Res. Lett. 28: 42154218.

Hendon HH (2000) Impact of air-sea coupling on the Madden-Julian oscillation in a general circulation model. J. Atmos. Sci. 57: 3939-3952.

Hendon HH, Liebmann B, Glick JD (1998) Oceanic Kelvin waves and the Madden-Julian Oscillation. J. Atmos. Sci. 55: 88-101.

Hendon HH, Salby ML (1996) Planetary-scale circulations forced by intraseasonal variations of observed convection. J. Atmos. Sci. 53: 1751-1758.
Heywood KJ, Barton ED, Allen GL (1994) South Equatorial Current of the Indian Ocean - A 50-day oscillation. Oceanologica Acta 17: 255-261.

Hosoda S, Minato S, Shikama N (2006) Seasonal temperature variation below the thermocline detected by Argo floats. Geophys. Res. Lett. 33: L13604. doi: 10.1029/2006GL026070

Hsu HH (1996) Global view of the intraseasonal oscillation during northern winter. J. Climate 9: 23862406.

Inness PM, Slingo JM (2003) Simulation of the MaddenJulian oscillation in a coupled general circulation model. Part I: Comparison with observations and an atmosphere-only GCM. J. Climate 16: 345-364.

Johnson ES, McPhaden MJ (1993) Structure of intraseasonal Kelvin waves in the Pacific Ocean. J. Phys. Oceanogr. 23: 608-625.

Kalnay E, Kanamitsu M, Kistler R, Collins W, Deaven D, Gandin L, Iredell M, Saha S, White G, Woollen J, Zhu Y, Chelliah M, Ebisuzaki W, Higgins W, Janowiak J, Mo KC, Ropelewski C, Wang J, Leetma A, Reynolds R, Jenne R, Joseph D (1996) The NCEP/NCAR 40-year reanalysis project. Bull. Amer. Meteorol. Soc. 77: 437-471.

Kessler WS, McPhaden MJ, Weickmann KM (1995) Forcing of intraseasonal Kelvin waves in the equatorial Pacific. J. Geophys. Res. 100: 10613-10631.

Kessler WS, Spillane MC, McPhaden MJ, Harrison DE (1996) Scales of variability in the equatorial Pacific inferred from the Tropical Atmosphere-Ocean buoy array. J. Climate 9: 2999-3024.

Kessler WS, Kleeman R (2000) Rectification of the MaddenJulian oscillation into the ENSO cycle. J. Climate 13: 3560-3575.

Kessler WS, McCreary JP (1993) The annual winddriven Rossby wave in the subthermocline equatorial Pacific. J. Phys. Oceanogr. 23: 1192-1207.

Kutsuwada K, McPhaden M (2002) Intraseasonal variations in the upper equatorial Pacific Ocean prior to and during the 1997-98 El Niño. J. Phys. Oceanogr. 32: 1133-1149.

Lau WKM, Waliser DE (2005) Intraseasonal variability in the atmosphere-ocean climate system. SpringerPraxis, Berlin.

Liebmann B, Smith CA (1996) Description of a complete (interpolated) OLR dataset. Bull. Amer. Meteorol. Soc. 77: 1275-1277.

Locarnini RA, Mishonov AV, Antonov JI, Boyer TP, Garcia HE (2006) World Ocean Atlas 2005, Volume 1: Temperature. NOAA Atlas NESDIS 61, U.S. Government Printing Office, Washington, D.C.. 
Madden RA, Julian PR (1971) Detection of a 40-50 day oscillation in the zonal wind in the tropical Pacific. J. Atmos. Sci. 28: 702-708.

Matthews AJ (2000) Propagation mechanisms for the Madden-Julian oscillation. Quart. J. Roy. Meteorol. Soc. 126: 2637-2652.

Matthews AJ (2004) The atmospheric response to observed intraseasonal tropical sea surface temperature anomalies. Geophys. Res. Lett. 31: L14107. doi: 10.1029/2004GL020474

Matthews AJ (2008) Primary and successive events in the Madden-Julian Oscillation. Quart. J. Roy. Meteorol. Soc. 134: 439-453.

Matthews AJ, Hoskins BJ, Masutani M (2004) The global response to tropical heating in the MaddenJulian Oscillation during northern winter. Quart. J. Roy. Meteorol. Soc. 130: 1991-2011.

Matthews AJ, Singhruck P, Heywood KJ (2007) Deep ocean impact of a Madden-Julian oscillation observed by Argo floats. Science 318: 1765-1769.

Matthews AJ, Meredith MP (2004) Variability of Antarctic circumpolar transport and the southern annular mode associated with the Madden-Julian oscillation. Geophys. Res. Lett. 31: L24312. doi: 10.1029/2004

McPhaden MJ (1999) Genesis and evolution of the 199798 El Niño. Science 283: 950-954.

McPhaden MJ (2002) Mixed layer temperature balance on intraseasonal timescales in the equatorial Pacific Ocean. J. Climate 15: 2632-2647.

McPhaden MJ, Taft BA (1988) On the dynamics of seasonal and intraseasonal variability in the eastern equatorial Pacific. J. Phys. Oceanogr. 18: 17131732 .

Meyers G, Phillips H, Smith N, Sprintall J (1991) Space and time scales for optimal interpolation of temperature - Tropical Pacific Ocean. Progress Oceanog. 28: $189-218$.

Reynolds RW, Rayner NA, Smith TM, Stokes DC, Wang W (2002) An improved in situ and satellite SST analysis for climate. J. Climate 15: 1609-1625.

Reynolds RW, Smith TM (1994) Improved global sea surface temperature analyses using optimum interpolation. J. Climate 7: 929-948.

Roundy PE, Kiladis GN (2006) Observed relationships between oceanic Kelvin waves and atmospheric forcing. J. Climate 19: 5253-5272.

Seo KH, Xue Y (2005) MJO-related oceanic Kelvin waves and the ENSO cycle: a study with the NCEP global ocean data assimilation system. Geophys. Res. Lett. 32: L07712. doi: 10.1029/2005GL022511

Shinoda T, Hendon HH, Glick J (1998) Intraseasonal variability of surface fluxes and sea surface tem- perature in the tropical western Pacific and Indian Oceans. J. Climate 11: 1685-1702.

Shinoda T, Hendon HH, Glick J (1999) Intraseasonal surface fluxes in the tropical western pacific and Indian oceans from NCEP reanalyses. Mon. Wea. Rev. 127: 678-693.

Shinoda T, Roundy PE, Kiladis GN (2008) Variability of intraseasonal Kelvin waves in the equatorial Pacific Ocean. J. Phys. Oceanogr. 38: 921-944.

Shinoda T, Hendon HH (1998) Mixed layer modeling of intraseasonal variability in the tropical Pacific and Indian Oceans. J. Climate 11: 2668-2685.

Shinoda T, Hendon HH (2001) Upper-ocean heat budget in response to the Madden-Julian oscillation in the western equatorial Pacific. J. Climate 14: 41474165.

Waliser DE, Murtugudde R, Strutton P, Li JL (2005) Subseasonal organization of ocean chlorophyll: Prospects for prediction based on the Madden-Julian Oscillation. Geophys. Res. Lett. 32: L23602. doi: 10.1029/2005GL024300

Wheeler M, Hendon HH (2004) An all-season real-time multivariate MJO Index: Development of an index for monitoring and precipitation. Mon. Wea. Rev. 132: 1917-1932.

Eforolnough SJ, Slingo JM, Hoskins BJ (2000) The relationship between convection and sea surface temperature on intraseasonal timescales. J. Climate 13: 2086-2104.

Woolnough SJ, Slingo JM, Hoskins BJ (2001) The organisation of tropical convection by intraseasonal sea surface temperature anomalies. Quart. J. Roy. Meteorol. Soc. 127: 887-907.

Yu X, McPhaden MJ (1999) Seasonal variability in the equatorial Pacific. J. Phys. Oceanogr. 29: 925-947.

Zhang C (2001) Intraseasonal perturbations in sea surface temperatures of the equatorial eastern Pacific and their association with the Madden-Julian oscillation. J. Climate 14: 1309-1322.

Zhang C (2005) Madden-Julian Oscillation. Rev. Geophys. 43: RG2003. doi: 10.1029/2004RG000158

Zhang C, Gottschalck J (2002) SST anomalies of ENSO and the Madden-Julian oscillation in the equatorial Pacific. J. Climate 15: 2429-2445. 
List of Figures

1 Longitude-depth sections along the equator (averaged $1.5^{\circ} \mathrm{S}$ to $1.5^{\circ} \mathrm{N}$ ) of timemean Argo (a) potential temperature $\left({ }^{\circ} \mathrm{C}\right)$, (b) salinity. See legends for shading. The thick line in (a) denotes the $20^{\circ} \mathrm{C}$ isotherm. Black shading denotes regions of land or missing data. . . . . . . . . . .

2 Hovmöller diagrams of the anomalous depth of the $20{ }^{\circ} \mathrm{C}$ isotherm from 1 January 2003 to 1 January 2007, averaged between $2{ }^{\circ} \mathrm{S}$ and $2{ }^{\circ} \mathrm{N}$, from (a) gridded Argo data, (b) TAO buoy data. Contour interval is $10 \mathrm{~m}$; see legend for shading. The solid lines indicate the propagation paths of positive eastward-propagating anomalies, and are identical in both panels. Equatorial OLR anomalies, averaged from $10{ }^{\circ} \mathrm{S}$ to $10{ }^{\circ} \mathrm{N}$, are hatched vertically below $-15 \mathrm{~W} \mathrm{~m}^{-2}$ and diagonally above $15 \mathrm{~W} \mathrm{~m}^{-2}$; see legend for hatching. 16

3 Phase-space diagram (RMM1,RMM2) of the Wheeler-Hendon MJO index for all weeks from January 2003 to December 2006. The phase space is divided into eight MJO phases, plus a central circle signifying weak MJO activity. The approximate location of enhanced convection for the MJO phases is indicated around the perimeter of the diagram. . . . . .

4 Composite anomaly maps of OLR and 1000-hPa streamfunction and vector wind, for each phase of the MJO, calculated over the period 2003-2006. Shading levels for OLR (in $\mathrm{W} \mathrm{m}^{-2}$ ) are indicated by the legend. OLR anomalies that are statistically significant at the $90 \%$ level are delineated by a thick contour. Streamfunction contour interval is $3 \times 10^{5} \mathrm{~m}^{2} \mathrm{~s}^{-1}$. Negative contours are dotted. Wind vectors are only plotted where either the zonal or meridional component is statistically significant at the $90 \%$ level. A reference wind vector of magnitude $2 \mathrm{~m} \mathrm{~s}^{-1}$ is shown in the lower right corner. . . .
5 Composite anomaly maps of Argo 10 dbar potential temperature. Contour interval is $0.1{ }^{\circ} \mathrm{C}$. Negative contours are dotted, and the first positive contour is at $0.05^{\circ} \mathrm{C}$. Shading is indicated by the legend. Anomalies that are statistically significant at the $90 \%$ level are delineated by a thick contour. Black shading denotes areas of land or missing data. . . . . . . . .

6 As Fig. 5 but for NOAA OI SST: (a) phase 4 , (b) phase $8 . \ldots . \ldots 20$

7 As Fig. 5 but for Argo 10 dbar salinity. Contour interval is 0.04 , and the first positive contour is at 0.02 . . . . . .

8 As Fig. 5 but for evaporation minus precipitation. Contour interval is $1 \mathrm{~mm} \mathrm{day}^{-1}$, and the first positive contour is at $0.5 \mathrm{~mm}$ day $^{-1}$. 22

9 Hovmöller diagrams of the depth anomaly of the $20{ }^{\circ} \mathrm{C}$ isotherm, time lagged with respect to $\mathrm{MJO}$ phase 1 , and averaged between $1.5^{\circ} \mathrm{S}$ and $1.5^{\circ} \mathrm{N}$, for (a) Argo, and (b) TAO, data. Contour interval is $2 \mathrm{~m}$. Negative contours are dotted, and the first positive contour is at $1 \mathrm{~m}$. Shading levels are indicated by the legend. The thick lines indicate the propagation paths of the anomalies, with a phase speed of $2.5 \mathrm{~m} \mathrm{~s}^{-1}$. . . . . . . . . .

10 Longitude-phase diagrams of two MJO cycles of Argo (a) depth of the $20{ }^{\circ} \mathrm{C}$ isotherm, and (b) 950 dbar potential temperature anomalies, averaged between $2{ }^{\circ} \mathrm{S}$ and $2{ }^{\circ} \mathrm{N}$. Contour interval is $2 \mathrm{~m}$ in (a), and $0.02{ }^{\circ} \mathrm{C}$ in (b). Negative contours are dotted, and the first positive contours are at $1 \mathrm{~m}$ in (a) and $0.01{ }^{\circ} \mathrm{C}$ in (b). Shading levels are indicated by the legends. The thick lines indicate the propagation of the D20 anomalies. . . .

11 Latitude-depth cross-section along $170^{\circ} \mathrm{W}$ of Argo potential temperature anomaly, for phase 5 of the MJO. Contours are at $\pm 0.02,0.05$ and $0.4{ }^{\circ} \mathrm{C}$. Negative contours are dotted. Shading levels are indicated by the legend. Black shading denotes regions of missing data. . . . . .

12 As Fig. 5 but for Argo surface dynamic height anomaly, relative to 950 dbar. Contour interval is $0.1 \mathrm{~m}$, and the first positive contour is at $0.05 \mathrm{~m}$. . . . . .

1 
13 As Fig. 12 but for Argo surface geostrophic zonal current. Contour interval is $2 \mathrm{~cm} \mathrm{~s}^{-1}$, and the first positive contour is at $2 \mathrm{~cm} \mathrm{~s}^{-1}$. 26

14 As Fig. 5 but for Argo 950 dbar potential temperature during MJO phase 8 . Contour interval is $0.02{ }^{\circ} \mathrm{C}$, and the first positive contour is at $0.01{ }^{\circ} \mathrm{C}$. . . . .

15 Longitude-depth cross-section along the equator (averaged $1.5^{\circ} \mathrm{S}$ to $1.5^{\circ} \mathrm{N}$ ) of Argo potential temperature anomaly. Shading levels are at $\pm 0.02,0.05$ and $0.4{ }^{\circ} \mathrm{C}$, indicated by the legend. Black shading denotes regions of land or missing data. Areas that are statistically significant at the $90 \%$ level are delineated by a thin contour. . . . . . . . . . .

16 As Fig. 15 but for Argo salinity anomaly. Shading levels are at $\pm 0.001,0.01$, and 0.04 , indicated by the legend. . . . . . .

17 Longitude-depth cross-section along the equator (averaged $1.5{ }^{\circ} \mathrm{S}$ to $1.5{ }^{\circ} \mathrm{N}$ ) of vertical displacement anomaly for phase 8 of the MJO, calculated from (a) potential temperature $\left(\Delta z_{\theta}\right)$, (b) salinity $\left(\Delta z_{S}\right)$. Contours are at $\pm 2,4$, and $8 \mathrm{~m}$. Negative contours are dotted. Shading levels are indicated by the legend. . . . 

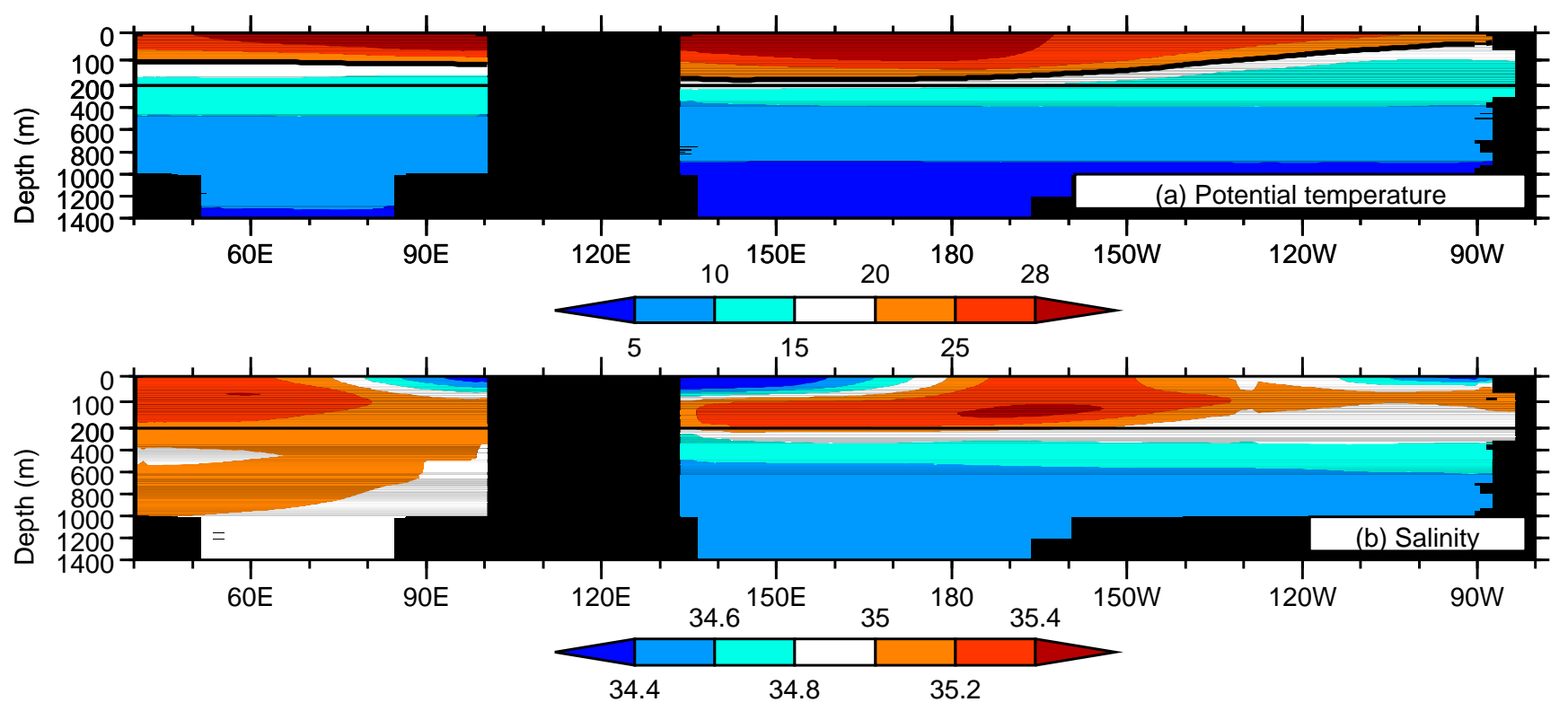

Fig. 1 Longitude-depth sections along the equator (averaged $1.5^{\circ} \mathrm{S}$ to $1.5^{\circ} \mathrm{N}$ ) of time-mean Argo (a) potential temperature ( $\mathrm{C}$ ), (b) salinity. See legends for shading. The thick line in (a) denotes the $20^{\circ} \mathrm{C}$ isotherm. Black shading denotes regions of land or missing data. 

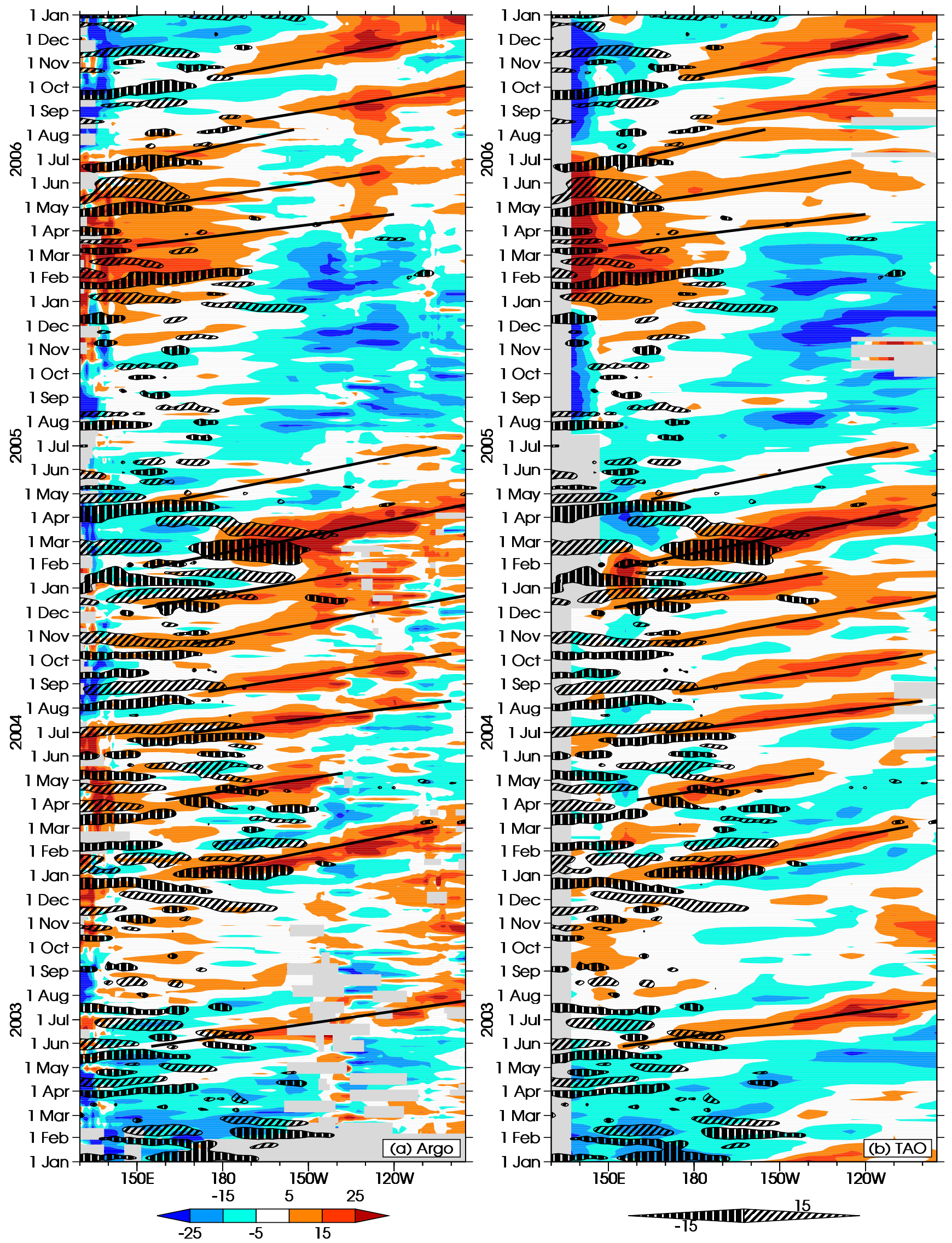

Fig. 2 Hovmöller diagrams of the anomalous depth of the $20^{\circ} \mathrm{C}$ isotherm from 1 January 2003 to 1 January 2007, averaged between $2{ }^{\circ} \mathrm{S}$ and $2{ }^{\circ} \mathrm{N}$, from (a) gridded Argo data, (b) TAO buoy data. Contour interval is $10 \mathrm{~m}$; see legend for shading. The solid lines indicate the propagation paths of positive eastward-propagating anomalies, and are identical in both panels. Equatorial OLR anomalies, averaged from $10^{\circ} \mathrm{S}$ to $10^{\circ} \mathrm{N}$, are hatched vertically below $-15 \mathrm{~W} \mathrm{~m}^{-2}$ and diagonally above $15 \mathrm{~W} \mathrm{~m}^{-2}$; see legend for hatching. 


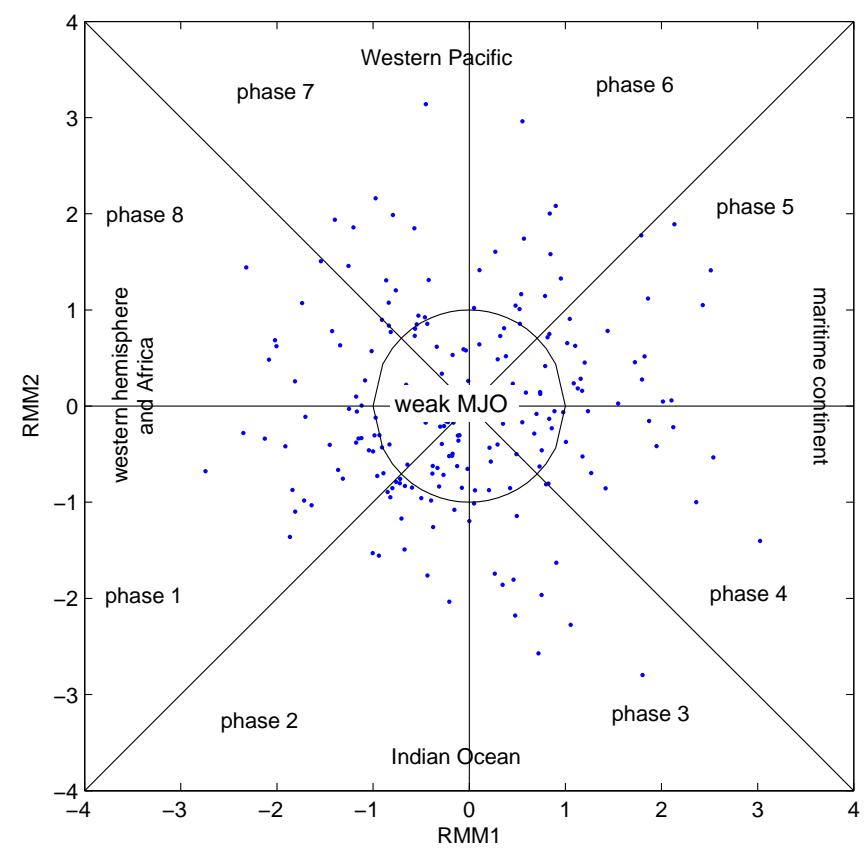

Fig. 3 Phase-space diagram (RMM1,RMM2) of the WheelerHendon MJO index for all weeks from January 2003 to December 2006. The phase space is divided into eight MJO phases, plus a central circle signifying weak MJO activity. The approximate location of enhanced convection for the MJO phases is indicated around the perimeter of the diagram. 

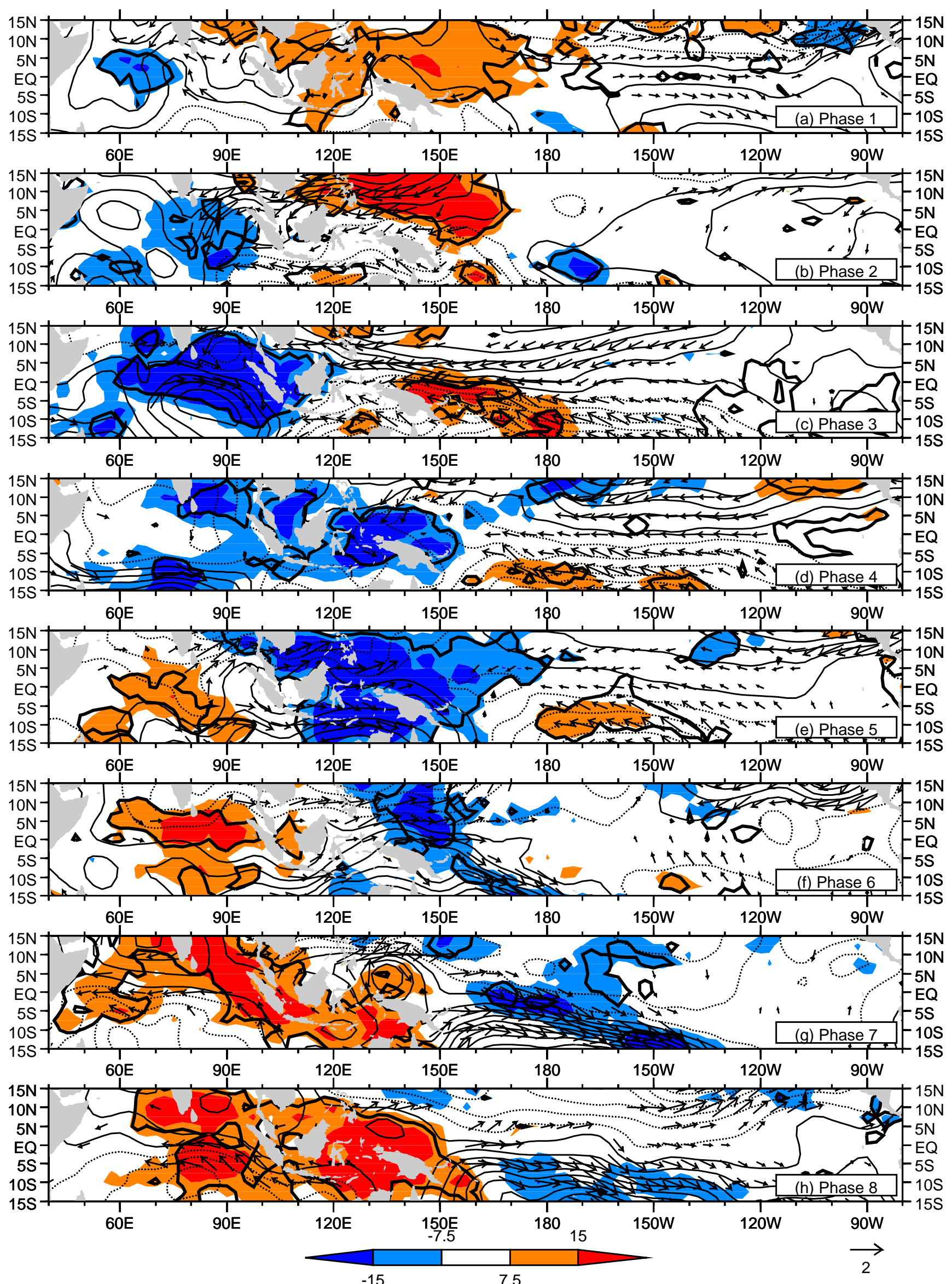

Fig. 4 Composite anomaly maps of OLR and 1000-hPa streamfunction and vector wind, for each phase of the MJO, calculated over the period 2003-2006. Shading levels for OLR (in $\mathrm{W} \mathrm{m}^{-2}$ ) are indicated by the legend. OLR anomalies that are statistically significant at the $90 \%$ level are delineated by a thick contour. Streamfunction contour interval is $3 \times 10^{5} \mathrm{~m}^{2} \mathrm{~s}^{-1}$. Negative contours are dotted. Wind vectors are only plotted where either the zonal or meridional component is statistically significant at the $90 \%$ level. A reference wind vector of magnitude $2 \mathrm{~m} \mathrm{~s}^{-1}$ is shown in the lower right corner. 

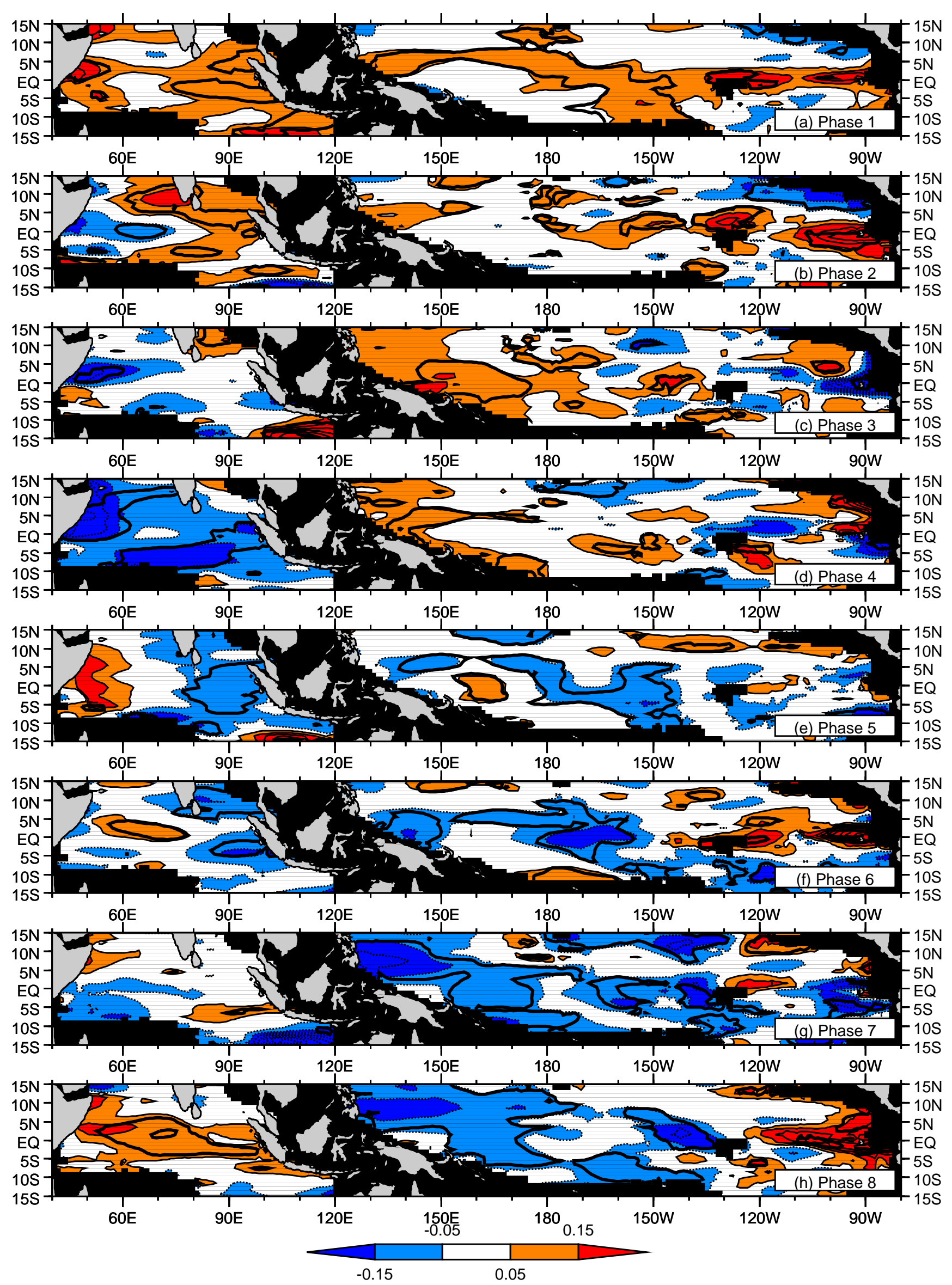

Fig. 5 Composite anomaly maps of Argo 10 dbar potential temperature. Contour interval is $0.1^{\circ} \mathrm{C} . \mathrm{Negative}$ contours are dotted, and the first positive contour is at $0.05{ }^{\circ} \mathrm{C}$. Shading is indicated by the legend. Anomalies that are statistically significant at the $90 \%$ level are delineated by a thick contour. Black shading denotes areas of land or missing data. 


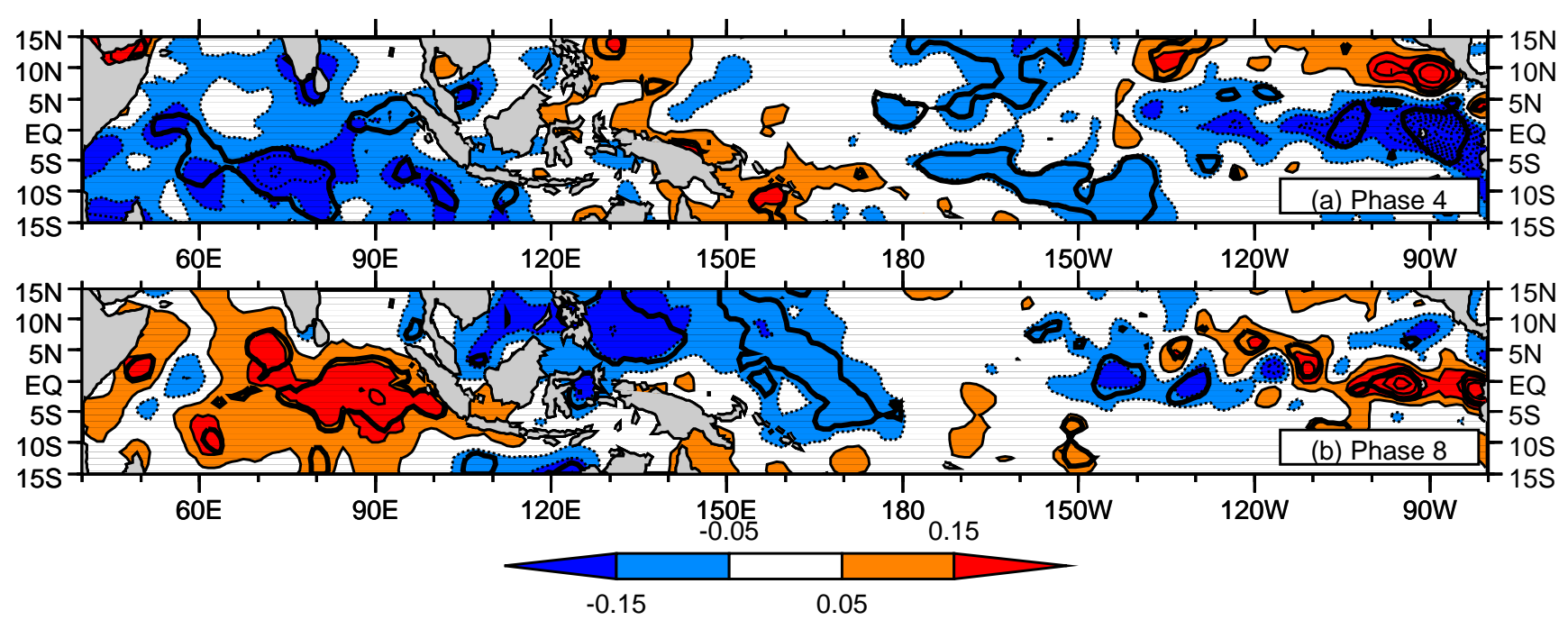

Fig. 6 As Fig. 5 but for NOAA OI SST: (a) phase 4, (b) phase 8. 

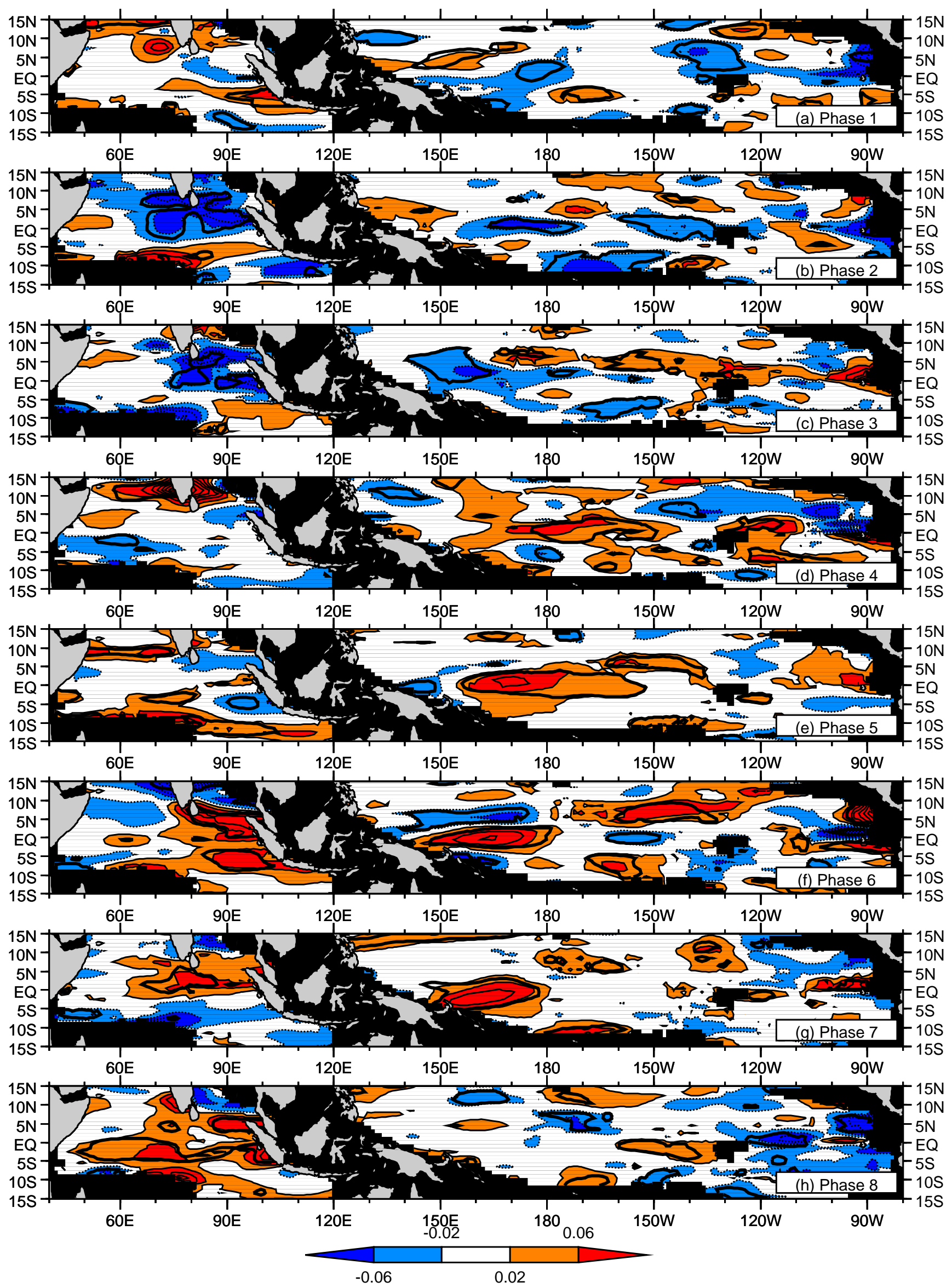

Fig. 7 As Fig. 5 but for Argo 10 dbar salinity. Contour interval is 0.04 , and the first positive contour is at 0.02 . 
15S-
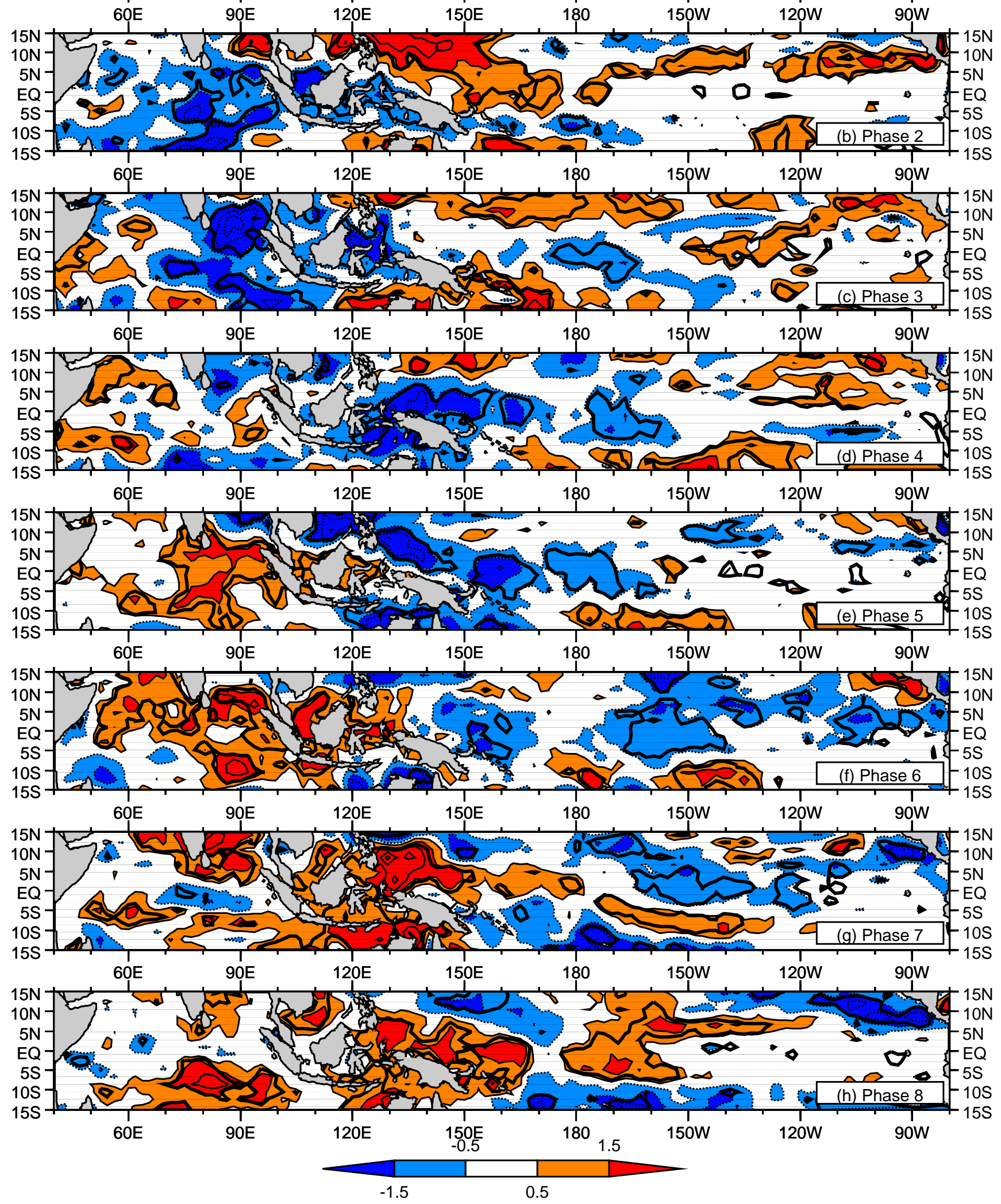

Fig. 8 As Fig. 5 but for evaporation minus precipitation. Contour interval is 1 mm day ${ }^{-1}$, and the first positive contour is at $0.5 \mathrm{~mm} \mathrm{day}^{-1}$. 


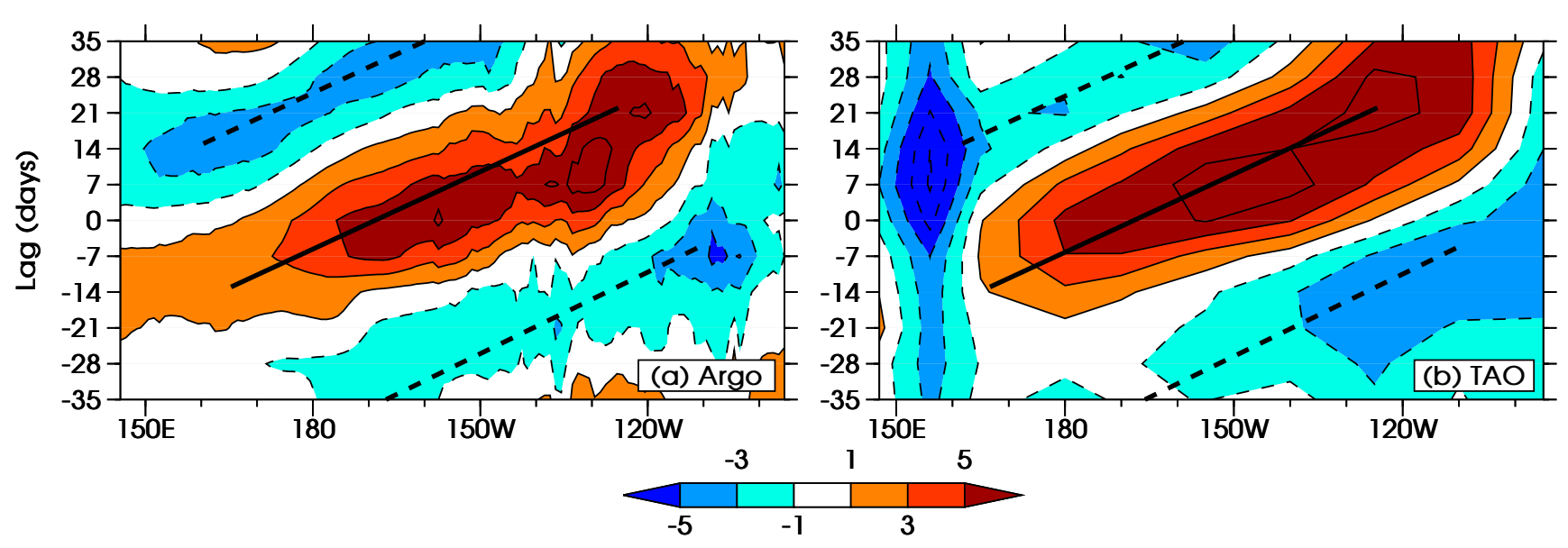

Fig. 9 Hovmöller diagrams of the depth anomaly of the $20^{\circ} \mathrm{C}$ isotherm, time lagged with respect to MJO phase 1, and averaged between $1.5^{\circ} \mathrm{S}$ and $1.5^{\circ} \mathrm{N}$, for (a) Argo, and (b) TAO, data. Contour interval is $2 \mathrm{~m}$. Negative contours are dotted, and the first positive contour is at $1 \mathrm{~m}$. Shading levels are indicated by the legend. The thick lines indicate the propagation paths of the anomalies, with a phase speed of $2.5 \mathrm{~m} \mathrm{~s}^{-1}$.
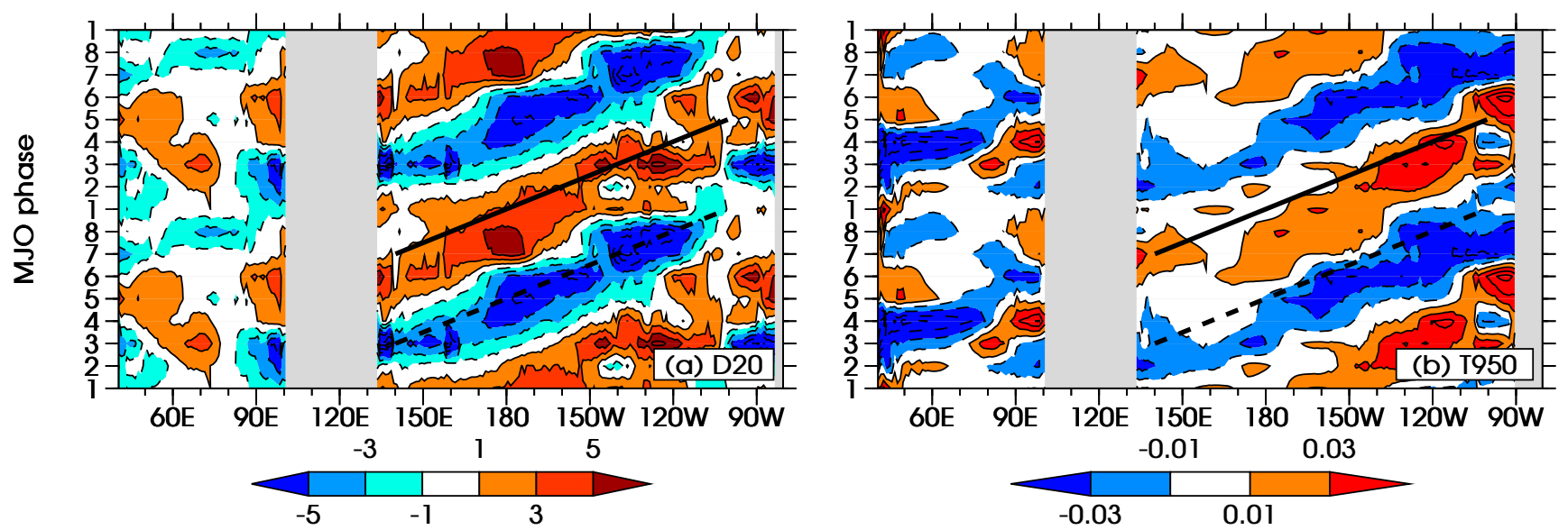

Fig. 10 Longitude-phase diagrams of two MJO cycles of Argo (a) depth of the $20^{\circ} \mathrm{C}$ isotherm, and (b) 950 dbar potential temperature anomalies, averaged between $2{ }^{\circ} \mathrm{S}$ and $2{ }^{\circ} \mathrm{N}$. Contour interval is $2 \mathrm{~m}$ in (a), and $0.02{ }^{\circ} \mathrm{C}$ in (b). Negative contours are dotted, and the first positive contours are at $1 \mathrm{~m}$ in (a) and $0.01{ }^{\circ} \mathrm{C}$ in (b). Shading levels are indicated by the legends. The thick lines indicate the propagation of the $D 20$ anomalies. 


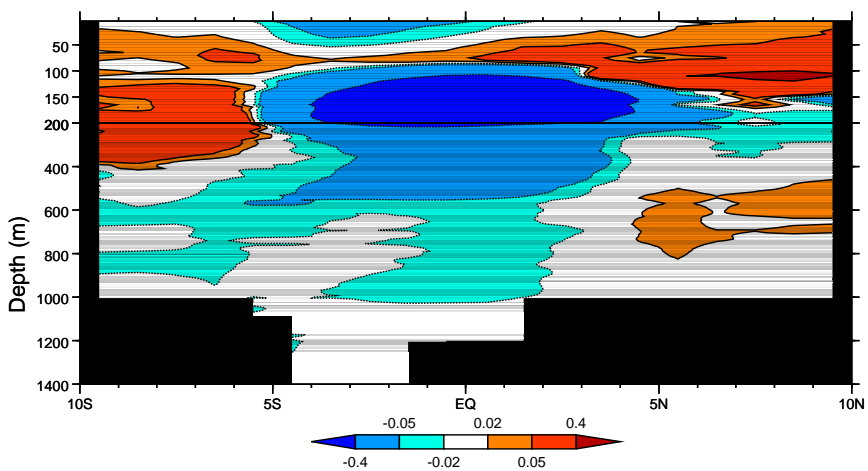

Fig. 11 Latitude-depth cross-section along $170^{\circ} \mathrm{W}$ of Argo potential temperature anomaly, for phase 5 of the MJO. Contours are at $\pm 0.02,0.05$ and $0.4{ }^{\circ} \mathrm{C}$. Negative contours are dotted. Shading levels are indicated by the legend. Black shading denotes regions of missing data. 

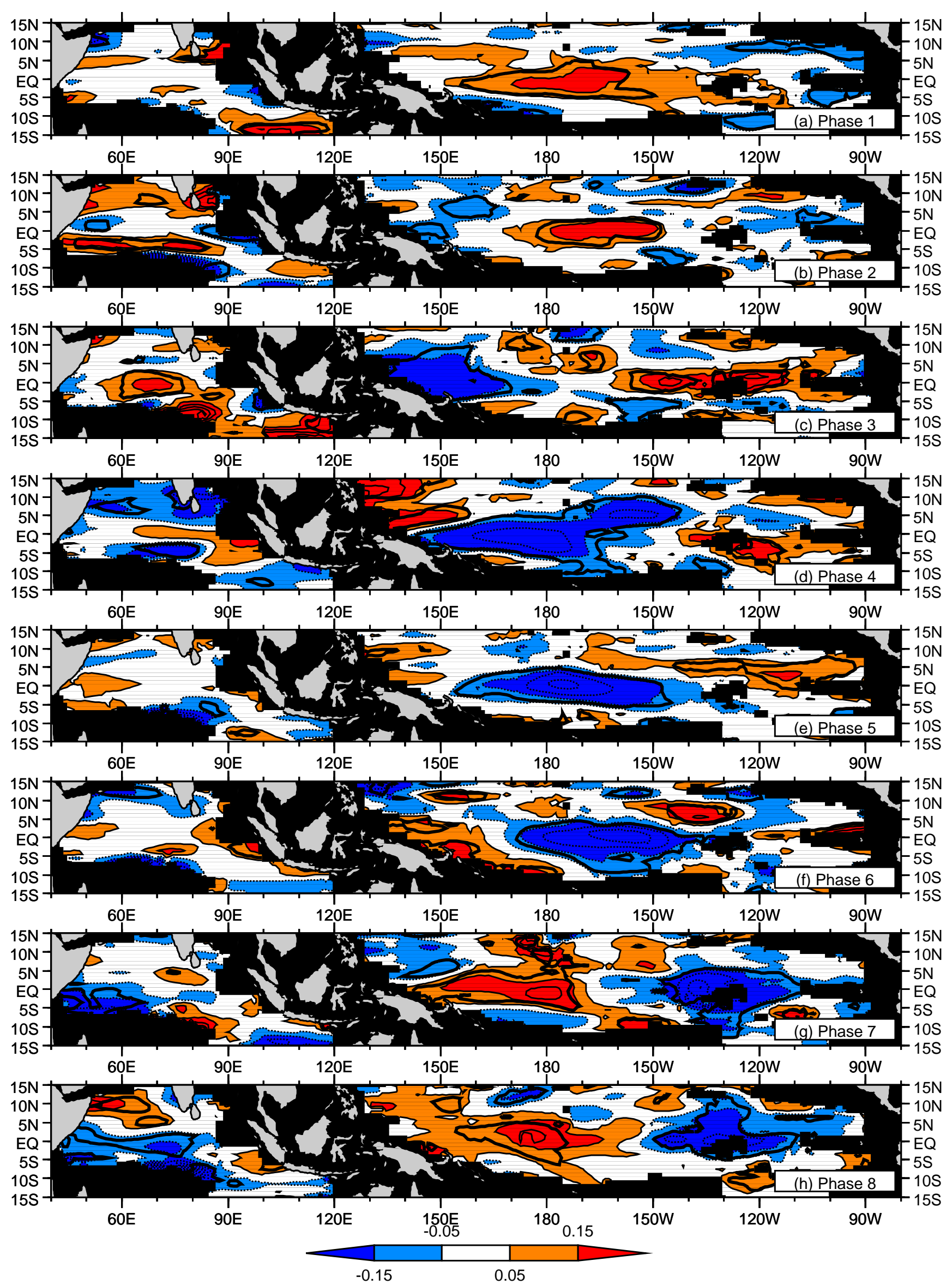

Fig. 12 As Fig. 5 but for Argo surface dynamic height anomaly, relative to 950 dbar. Contour interval is $0.1 \mathrm{~m}$, and the first positive contour is at $0.05 \mathrm{~m}$. 

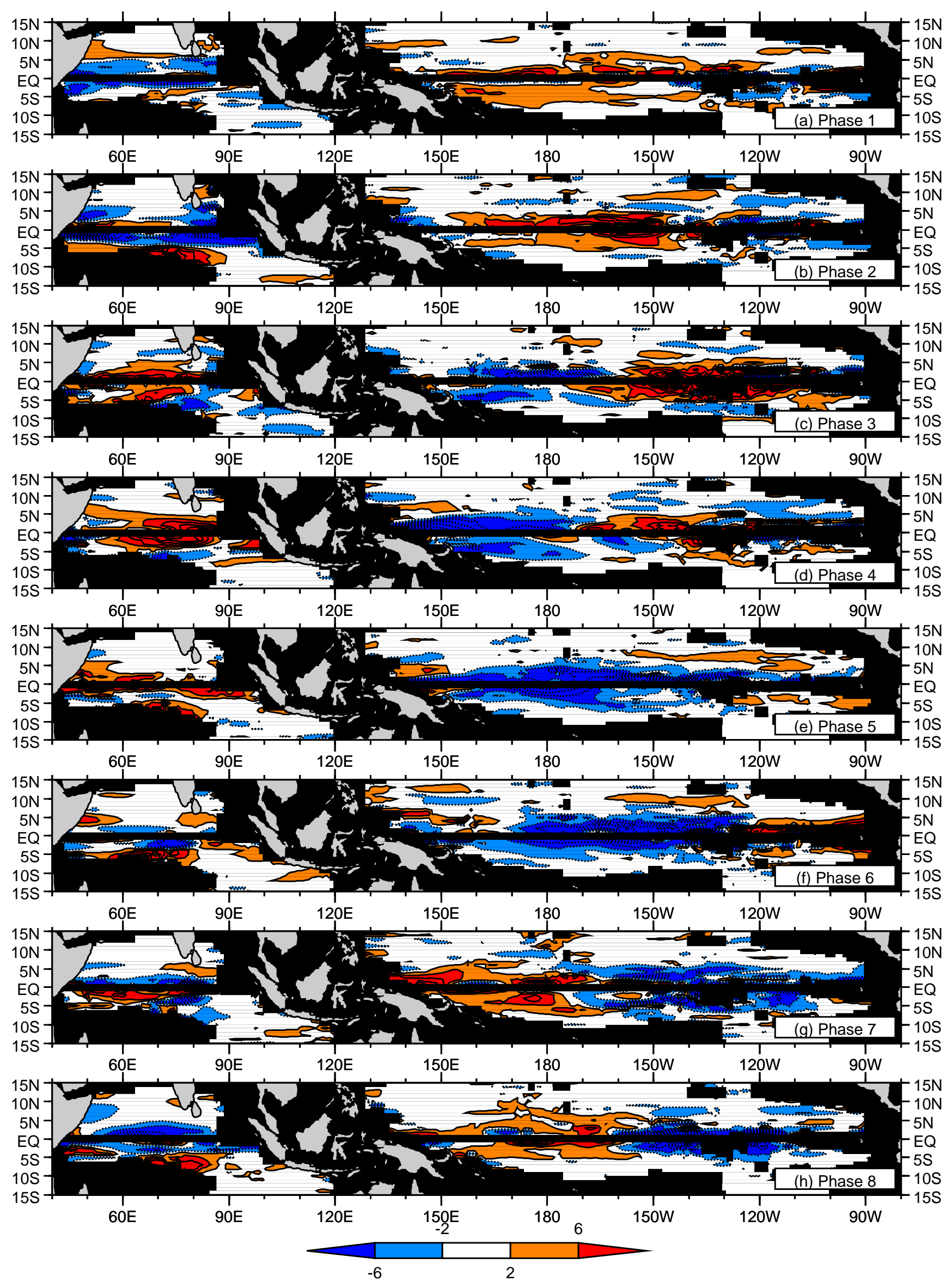

Fig. 13 As Fig. 12 but for Argo surface geostrophic zonal current. Contour interval is $2 \mathrm{~cm} \mathrm{~s}^{-1}$, and the first positive contour is at $2 \mathrm{~cm} \mathrm{~s}^{-1}$. 


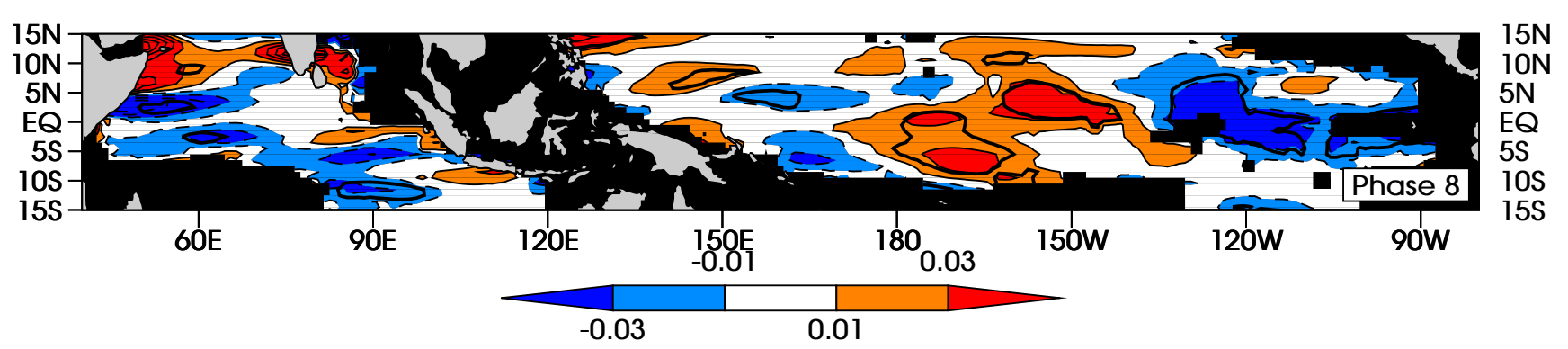

Fig. 14 As Fig. 5 but for Argo 950 dbar potential temperature during MJO phase 8. Contour interval is $0.02{ }^{\circ} \mathrm{C}$, and the first positive contour is at $0.01{ }^{\circ} \mathrm{C}$. 

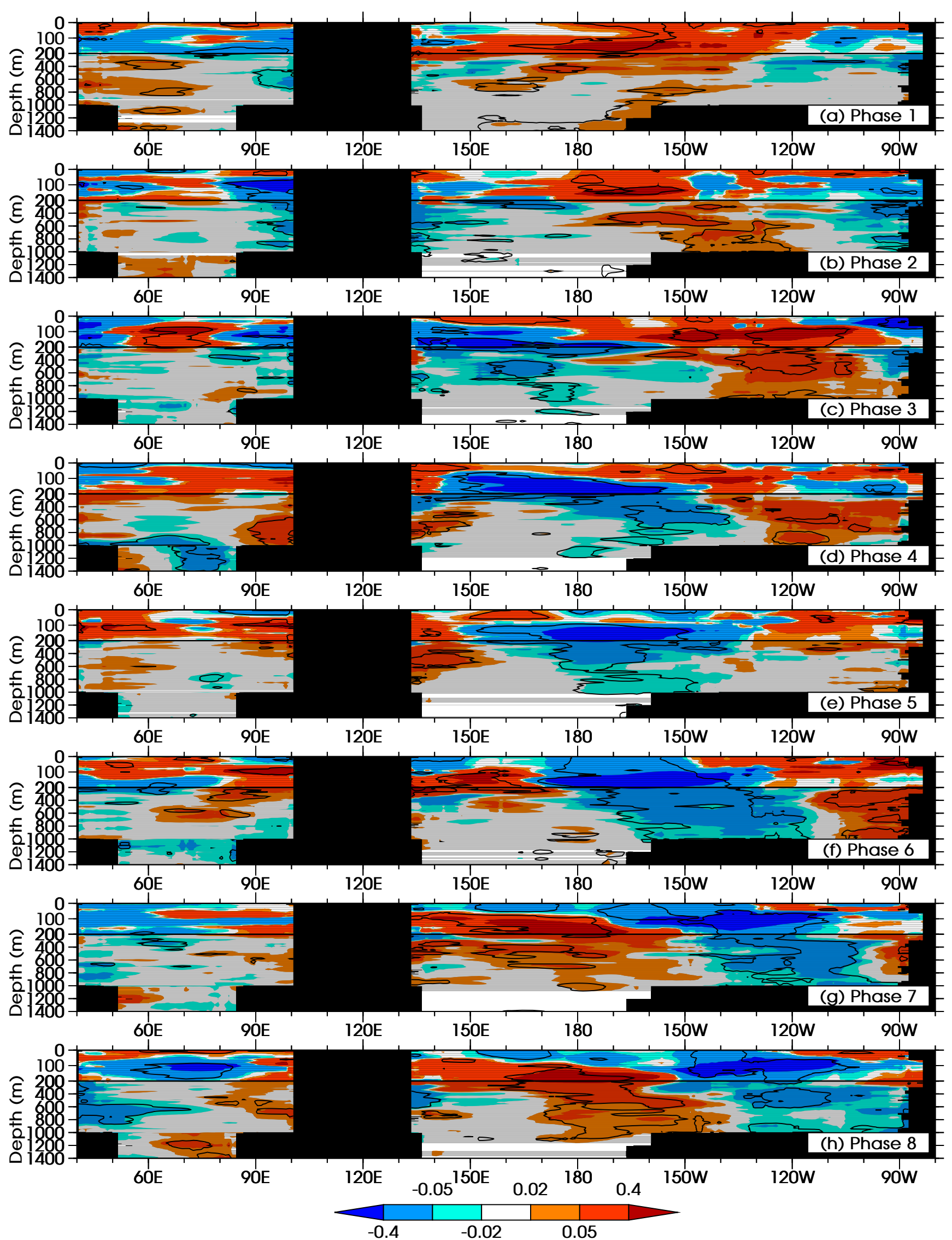

Fig. 15 Longitude-depth cross-section along the equator (averaged $1.5^{\circ} \mathrm{S}$ to $1.5^{\circ} \mathrm{N}$ ) of Argo potential temperature anomaly. Shading levels are at $\pm 0.02,0.05$ and $0.4^{\circ} \mathrm{C}$, indicated by the legend. Black shading denotes regions of land or missing data. Areas that are statistically significant at the $90 \%$ level are delineated by a thin contour 

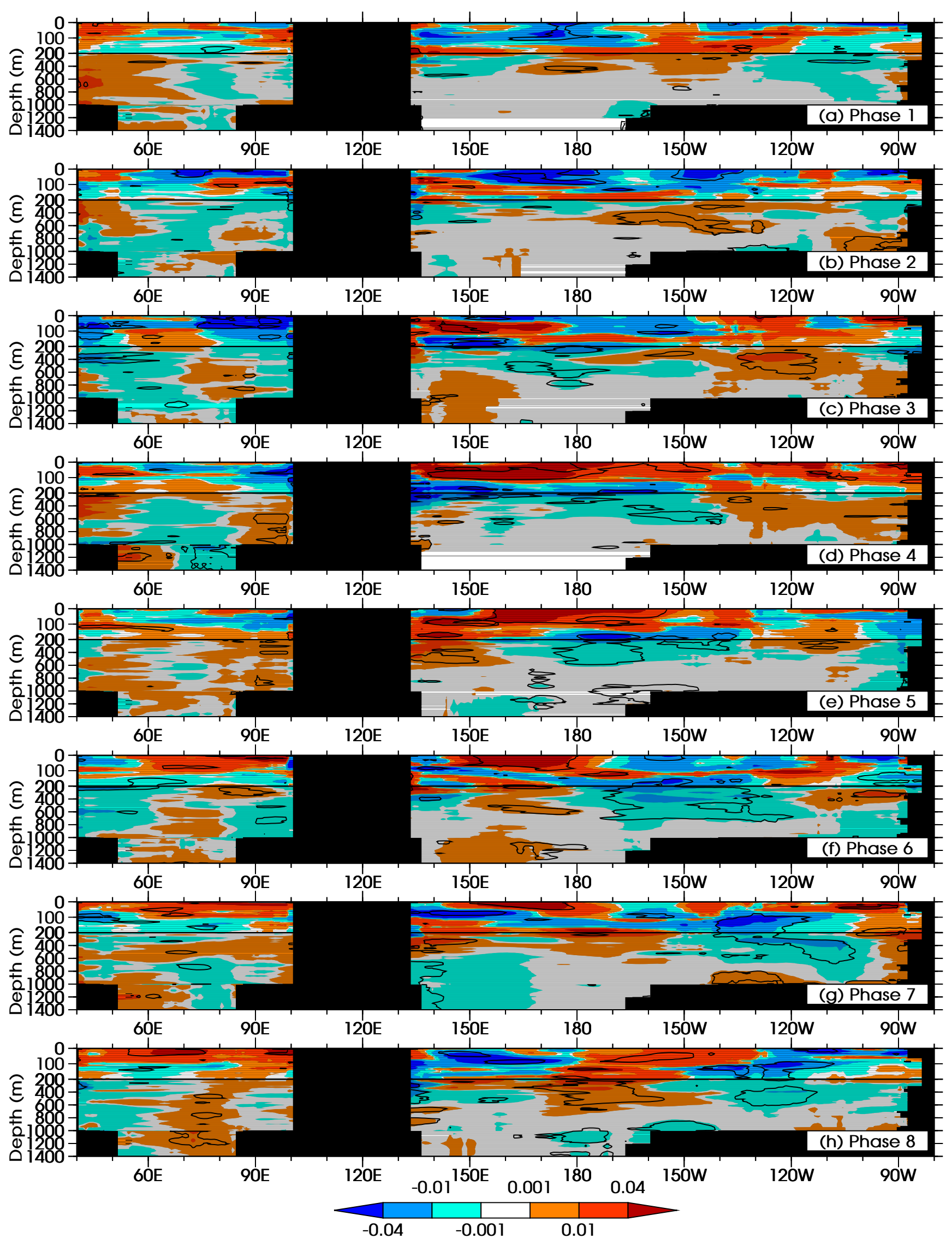

Fig. 16 As Fig. 15 but for Argo salinity anomaly. Shading levels are at $\pm 0.001,0.01$, and 0.04, indicated by the legend. 


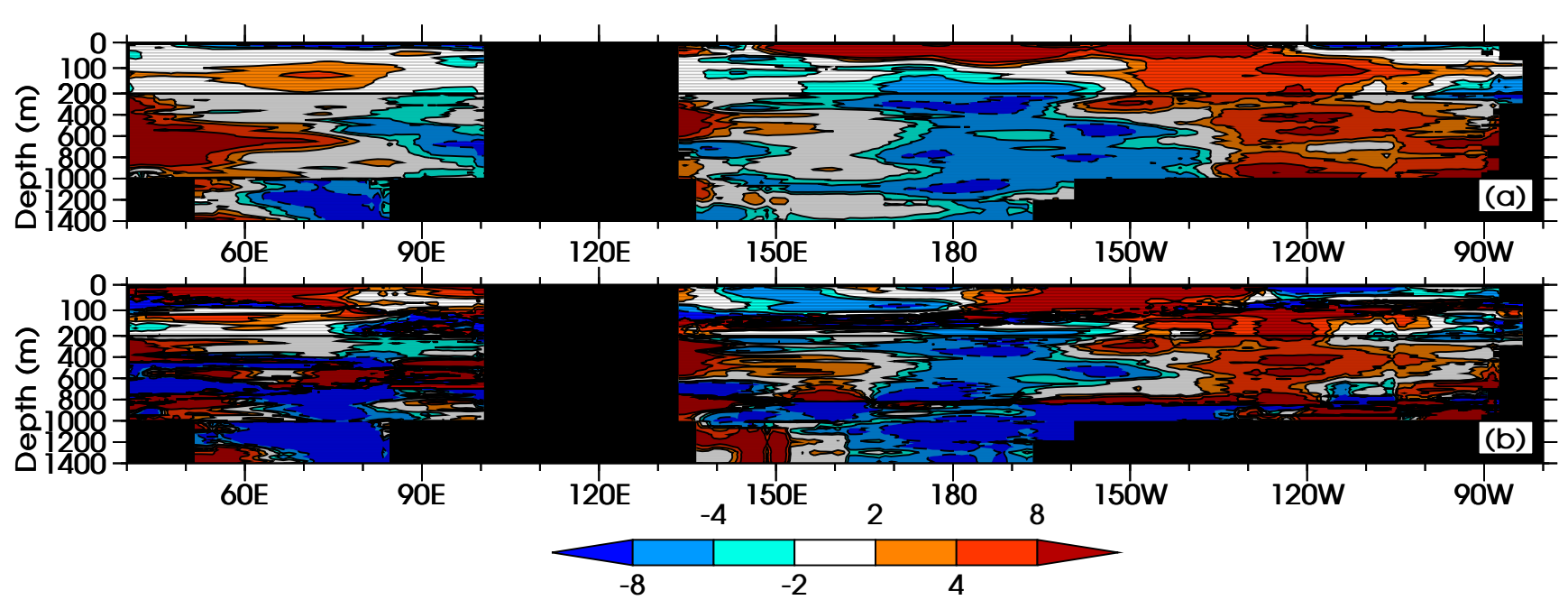

Fig. 17 Longitude-depth cross-section along the equator (averaged $1.5^{\circ} \mathrm{S}$ to $1.5^{\circ} \mathrm{N}$ ) of vertical displacement anomaly for phase 8 of the MJO, calculated from (a) potential temperature $\left(\Delta z_{\theta}\right)$, (b) salinity $\left(\Delta z_{S}\right)$. Contours are at $\pm 2,4$, and $8 \mathrm{~m}$. Negative contours are dotted. Shading levels are indicated by the legend. 